\title{
EL REGENERACIONISMO EDUCATIVO EN LA RIOJA Y LA ASOCIACIÓN DE MAESTROS PÚBLICOS RIOJANOS
}

\author{
Ángel Lázaro Martínez \\ Universidad de Alcalá \\ María José Mudarra Sánchez \\ Universidad de Alcalá \\ Magdalena Sáez de Jubera \\ Universidad de La Rioja
}

\section{Introducción}

En La busca, Pío Baroja, ante la descripción de una zapatería de los madriles que anunciaba sus servicios con el lema A la regeneración del calzado, hace el siguiente comentario:

"El historiador del porvenir, seguramente, encontrará este letrero una prueba de lo extendida que estuvo en algunas épocas cierta idea de regeneracionismo nacional, y no le asombrará que esa idea, que comenzó a querer reformar y regenerar la constitución y la raza española, concluyera en la muestra de una tienda de los barrios bajos, en donde lo único que se hacía era reformar y regenerar el calzado".

La novela, publicada por primera vez por entregas en el periódico El Globo, se escribió entre 1903 y 1905, período en el que diversos "regeneracionismos" y "antigeneracionismos" se expandían por España, manifestando la ebullición intelectual en torno a la descomposición de la identidad nacional que se simbolizó en el "desastre" del 1898, con las consecuencias que generó el Tratado de París y que consumó la descolonización de España en América y Oceanía. Ante la desorientación caótica y la desmoralización nacional se concibió, casi utópicamente, que la reconstrucción del país se debía basar en una nueva concepción de la Educación, redentora de los "males que aquejaban a España", extendiéndose un clamor de recuperación nacional, la regeneración del país, 
movimiento surgido del desmoronamiento moral, económico y político que, a finales del XIX, culminaba el derrumbamiento y desplome del "esqueleto de un gigante" cual era España, como había indicado Cadalso en el XVIII.

Pero, en esta ocasión, nuestras pretensiones, aunque encuadradas en el regeneracionismo riojano, como pretexto, intentan aportar cuestiones metodológicas cualitativas. En este estudio se abordan dos cuestiones básicas: una referida al contenido temático y otra concerniente a la metodología de investigación histórica. De forma más precisa los objetivos del estudio son los siguientes:

- Revisar metodológicamente la investigación histórica, analizando textos y fuentes por medio de la categorización y el proceso informático del Programa Atlas*ti. Este programa realiza operaciones hermenéuticas a partir del establecimiento de categorías de interpretación de los contenidos textuales y la ponderación secuencial establecida por los investigadores.

- Analizar el regeneracionismo educativo en La Rioja, manejando las aportaciones del contexto asociativo del Magisterio Riojano y su órgano de expresión, como es el Boletín (período de 1898-1902), subrayando los tópicos regeneracionistas.

Para corroborar estos supuestos del estudio desarrollamos nuestras aportaciones en tres apartados:

- En una primera parte se presenta la situación político-social del regeneracionismo, ubicando la caracterización del movimiento educativo del magisterio español y, en concreto, del riojano, ante la debacle de los acontecimientos del 98.

- En un segundo apartado se describe la Asociación del Magisterio Público Riojano y sus aportaciones al Regeneracionismo a través de las actividades que reflejaron en su Boletín quincenal, que permaneció durante cinco años, con precarios medios y con gran dosis de entusiasmo. Este Boletín ha sido analizado a partir de microfichas filmadas de los textos originales, localizados en la Hemeroteca Municipal de Madrid y en los fondos dependientes del Instituto de Estudios Riojanos.

- En una tercera parte, más extensa, realizamos un análisis metodológico de contenido, según los textos de dicho Boletín. El estudio, metodológicamente, se plantea, como en otros de aproximación histórica que hemos realizado, de forma concéntrica: partiendo de un núcleo temático -primer anillo- se elaboran varios ejes de discusión; en un "segundo anillo", se comentan los mismos temas apuntados en el círculo primero, pero especificando algunos detalles de concreción que incluyen la indagación y búsqueda de fuentes; en el "tercer anillo" se analiza, siguiendo las pautas de un programa informático, la información recogida en las fuentes, (en esta ocasión, el "Boletín de la Asociación del Magisterio Público Riojano"), por medio del Programa Atlas*ti. Este atrevimiento metodológico 
pretende conjugar los procedimientos de análisis de investigación cualitativa, aplicando nuevos recursos técnicos con las clásicas indagaciones históricas, obteniendo más precisión en las conclusiones localizadas.

\section{Regeneracionismo y educación}

Regenerar es un tránsito hacia un nuevo foco de la personalidad. En la perspectiva social, regenerar es el soporte espiritual de una política, o la rectificación, con pretensiones de mejora, de una técnica; histórica y concretamente, regenerar se podría entender como la revisión cautelar de las identidades nacionales del siglo XIX. Pero, en sentido amplio y psicológico, regenerar supone una reforma estructural de la personalidad y, socialmente, se podría aceptar que la regeneración se refiere a las características colectivas en un sistema; no implica necesariamente el cambio de la estructura, sino la revisión, rectificación y rediseño de las funciones que dinamizan la estructura. Organizativamente, regenerar es coordinar, ensamblar, más eficaz y eficientemente, las partes de un todo para lograr una "calidad total", en términos actuales de evaluación institucional actual, del funcionamiento de la estructura de un sistema. En síntesis, regenerar es dar nuevo de ser a algo que degeneró, actualizando sus funciones de forma que se logre mejorar sus cometidos.

Desde el enfoque histórico, el Regeneracionismo, aunque se inició desde la revolución de 1854 y, especialmente, desde la Restauración de 1874, se entiende como clave del sentido y quehacer de la identidad nacional española. El Regeneracionismo, como manifestación de la reconstrucción del país, se interpretaba como soporte de la progresía hasta que los acontecimientos del desastre del 98 estimularon sentimientos globales nacionalistas, reforzando, no obstante, los particulares. Por otra parte, animó la reconstrucción nacional como postulado de la acción de los conservadores.

Esta elemental apreciación manifiesta que el regeneracionismo es un movimiento complejo, que tiene diversas aportaciones y conexiones con otros movimientos similares en la agitada Europa de la segunda mitad y finales del XIX, con oscilaciones de intensidad, y que se manifiesta en acontecimientos significativos, según las peculiaridades nacionales, durante la evolución contemporánea de Europa. Se podría indicar, analógicamente, que el regeneracionismo, en España, es como una curva gaussiana cuya curtosis se localiza en los acontecimientos de 1898.

Uno de los sectores sociales de mayor interés renovador fue la tendencia a mejorar las propuestas de equiparación del soporte económico y cultural de la sociedad, aunque con planteamientos divergentes: por una parte, se constata en el regeneracionismo una línea de socialización que tiende a la disolución de los nacionalismos particulares y que, durante todo el siglo, se perciben como algo exótico; sin embargo, por otra, en el otro polo, se arraiga el nacionalismo "renaciente", como autoafirmación de los sentimientos "fronterizos" y contorneantes 
de Europa (patria igual a lengua, religión, etnia, territorio, tradición), como son todas las culturas balcánicas, nórdicas, mediterráneas, atlánticas, en conjunto, periféricas y tradicionalistas, que asumen lo cultural como fundamento de la entidad de resurgimiento de las propuestas políticas y sociales conservadoras. Otra línea divergente es el "imperialismo de las denominadas culturas eruditas", dominantes, que van, durante el siglo XIX, imponiendo una cultura de masas, positivista, técnica y progresista, generando el resurgimiento de una cultura europea, y que, por cuya hegemonía, política y social, provoca el enfrentamiento de los Estados Europeos. Paul Gerbod (1977) mantiene que la cultura europea alcanza su punto de inflexión en el período de entreguerras (entre la de "Sedan", 1870, y la "Gran Guerra", la de 1914"), entendiendo la caracterización cultural en un sentido amplio y diverso. Para Gerbod, hay que concebir la cultura como "el conjunto de costumbres, creencias, instituciones, ideologías y técnicas relativas a todos los sectores de la vida social y de relación que comparten y se transmiten mutuamente los miembros de una sociedad" (Gerbod, 1977, VII).

En este cruce de entendimientos aparece, centrándose en la diversidad, el regeneracionismo español. El movimiento percibe un cierto atraso al comparar España con Europa, y se detectan las deficiencias, provocando desazón e impulso renovador. Ejemplos clásicos, desgarrados y desesperados, son los trabajos de Ganivet y Costa. Ángel Ganivet, en el 1897, publica El Idearium español, donde clama por la recuperación de las formas de lo español y reclama una renovación educativa. Costa denuncia los soportes económicos basados en el caciquismo y en las costumbres de dependencia arbitraria (todavía, a comienzos del siglo XX, algunos viajeros, en sus estudios antropológicos, como Gerald Brenan que, en Al Sur de Granada, 1957, explica la vida social y política de España según el "caciquismo" imperante). Este retraso irrita a Costa que solicita más "despensa y escuela" como medios para promocionar la economía y mejorar la educación.

Probablemente fue Joaquín Costa el representante más significativo del regeneracionismo educativo, entendido como movimiento ideológico de reconstrucción social al que cabría calificar como beligerante ante el caciquismo del sistema político de finales del XIX. Su austero y utópico programa de "despensa y escuela", era poco atractivo para los partidos. Por ello, en 1903, renunció al escaño para el que había sido elegido en la candidatura republicana, y se retiró de la política, a la casi soledad de su casa de Graus, en Huesca, desde donde siguió ejerciendo su influencia con artículos, cartas, notas o discursos; sus escritos pedagógicos se agruparían en 1916 en la antología Maestro, escuela y patria. Su fogosa y vehemente personalidad ejerció una clara influencia regeneracionista en las intenciones educativas del magisterio español y, probablemente, su cercanía geográfica y su autoridad moral, también sería estímulo para el magisterio riojano, como lo reflejan los artículos que publicó en el "Boletín Riojano" (Un ejemplo es el artículo aparecido en el número 55 del 10 de noviembre de 1900). 
El Regeneracionismo fue un movimiento que pretendía conseguir la transformación interna de la persona para proyectarse luego sobre el resto de las actividades humanas, entendiendo que la escuela era el instrumento básico de transformación, tanto individual como colectivamente. El regeneracionismo inducía hacia el pragmatismo en lo económico y estimulaba un giro radical en la tradicional política 'quijotesca' española hacia terrenos e intereses más cercanos y directos. Muestra de esto es una noticia que aparece publicada en el ejemplar número 3 del "Boletín Riojano" del 1 de mayo de 1899 (día del trabajador), bajo el epígrafe La Asociación Marcha, que dice:

"Consuela, en medio de las desventuras nacionales, ver surgir clases Ilenas de vida y valor para reconstituir el país. Una de estas clases -lo decimos con noble orgullo- la del Magisterio primario. En todas las provincias se oyen los gritos de ;Asociación! ¡Asociación!; y en todas van respondiendo generosamente el profesorado de modo que es de esperar que sea un hecho la Asociación Nacional. En la de Logroño, con satisfacción podemos decirlo, nunca se ha visto más atracción ni más entusiasmo, más unidad de miras ni mejor voluntad, más fe en los principios ni más resolución para realizarlos ¡Adelante!".

Son notas de la influencia histórica del "desastre" del 98 en España, pero los precedentes y consecuencias tienen otras variables en América, que se entrecruzan y se desarrollan de forma diferente. François Chevalier (1977) señala los fenómenos de enfrentamiento entre la transculturación y la aculturación que da origen al orgullo de una nueva cultura, similar y enfrentada a la europea-española, culminando en los movimientos criollos de independencia; psicoanalíticamente, se podría decir que es la reinterpretación inconsciente y colectiva de una cultura hacia otra. El mismo autor, refiriéndose a México $(1977,315)$ señala que el "guadalapanismo [culto a la Virgen de Guadalupe] aparece como una prolongación de España en México, pero dirigido finalmente contra la metrópoli: ambivalencia de un país profundamente hispanizado, pero rival de España en nombre de su pasado indoamericano". Estas situaciones político-culturales tienen consecuencias, tanto sociales como educativas, bien a un lado, bien al otro del Atlántico, influyendo en la exaltación regeneracionista.

El regeneracionismo fue "una moda de larga duración". En el período anterior y posterior al 98, en ese "espacio generacional" conviven varias generaciones. El "espíritu regeneracionista encuentra plena justificación de sus tesis desde 1890 a 1895. La rápida reconversión al regeneracionismo satisfacía a una parte de la opinión que buscaba por todos los medios un cauce de salvación, una salida; desde los tradicionalistas a los reformistas, el regeneracionismo, frecuentemente derivado en regionalismo o nacionalismo, ocupa la primera plaza de la cultura nacional " (Martínez Cuadrado, 1974, 541).

Las inquietudes son diversas, se entrelazan y se superponen o, incluso, se reconvierten en tendencias diferentes. Este proceso de regeneración, en donde 
el fomento de la alfabetización y la extensión de la enseñanza contribuían a la búsqueda de un nuevo estilo peculiar de lo español, se subrayaba, durante el siglo XIX, con la tenue implantación de los principios democráticos, con la torpe erradicación de una economía caciquil y artesanal o con la incipiente feminización de la sociedad; San Román (1998) analiza los orígenes del proceso de feminización docente en España y señala que alcanza su mayor expansión en el tipo de maestra que denomina "racional-intuitiva", en sentido kantiano, y que se manifiesta con mayor vigor en el último cuarto del siglo XIX. Todas estas movimientos van conformando un particular y paulatino proceso social, que se va consolidado durante el XX, contribuyendo a la regeneración de lo español por medio de la educación.

El magisterio español es dubitativo respecto a su papel en el regeneracionismo por diversos motivos: por una parte, se deja arrastrar por la corriente, riada más bien, de los entusiasmos respecto a reabrir un nuevo espíritu renovador: por otra, su apego al tradicional conservadurismo le retrae para adoptar reformas tajantes; por otra, el lenguaje y las vivencias directas de Costa le atraen más que las argumentaciones de los intelectuales (subliminalmente los maestros dudan de que sus esfuerzos sean reconocidos por la sociedad y por los universitarios); por otra, las respuestas son muchas y las soluciones ofertadas "al problema de España" van desde el iluminismo entusiasta hasta el pesimismo desesperado. Costa, en el 1897, escribe, en un afamado prólogo a Queral, La Ley del embudo, que España ha muerto.

Estas vacilaciones del magisterio caracterizaron un nuevo tipo de regeneracionismo, diferente al populista y guasón, al intelectual, al nacionalista-regional y al polemista-político. El regeneracionismo del magisterio se siente más solidario que integrado con un regeneracionismo global e intenta aportar, desde enfoques pedagógicos diversos, su solución a la quebrada España con soluciones cuasi alegóricas: fiesta del árbol, identificación de la enseña... Casi siempre estos movimientos, pintorescos y aislados, se mantienen con una vorágine de iniciativas asociacionistas, como la constitución de Asociaciones y el liderazgo entusiasta de algunos maestros, (como el caso de Esteban Oca, en La Rioja, fundador, impulsor y mantenedor de la Asociación Riojana y de su Boletín). Coincidimos con Del Pozo (2000) cuando indica que "el movimiento regeneracionismo del magisterio fue un movimiento paralelo al regeneracionista intelectual" (2000, 83). De hecho, en la transición del XIX al XX, existían, dentro del magisterio español, multitud de iniciativas, divergencias y diferencias, aunque también de similitudes y semejanzas, especialmente en sus empeños de búsqueda y consolidación de lo español.

En este contexto y con estas inquietudes, Esteban Oca y otros entusiastas fundan la Asociación del Magisterio público riojano, organizan la actividad, establecen un mapa regional de coordinadores y comienzan a reclamar patrocinadores a su Boletín. 


\section{La Asociación del Magisterio Público Riojano}

La Asociación se gestó después del "desastre del 98", durante los primeros meses de 1899, con la intención de regenerar La Rioja y España, en concordancia con los sentimientos de los maestros riojanos. Los socios fundadores fueron 253, 135 hombres y 118 mujeres ${ }^{1}$. Existían dos clases de socios: los activos, donde se incluían todos los maestros e interinos que realicen su trabajo en la escuela pública de la capital y de los pueblos riojanos, y los socios pasivos, que comprendía a los que después de Ilevar cierto tiempo en la Sociedad, obtuvieran la jubilación. Su primer y único presidente fue Esteban Oca, destinado en Logroño, promotor de la Asociación, también elegido como director del Boletín de la Asociación.

Aunque tenían diversas intenciones asociativas, su principal y casi único medio de expresión y consolidación fue el Boletín, órgano de expresión y unión entre los socios, en el que se recogían las inquietudes y vida social del magisterio riojano y en el que vamos a centrar nuestro estudio, inicialmente de forma descriptiva y, posteriormente, realizando un análisis de su contenido.

\section{Boletín de la Asociación del Magisterio Público Riojano}

De forma sintética y concisa se reflejan los datos del Boletín de la Asociación como material básico de nuestro estudio, por lo que, de forma cuasi-telegráfica, señalamos sus características, tanto de forma descriptiva como analíticamente. Se indica que las fuentes consultadas han sido la colección completa que se conserva en la Hemeroteca Municipal de Madrid, de donde hemos obtenido microfilms, y los fondos existentes en la Biblioteca del Instituto de Estudios Riojanos.

\section{Ficha descriptiva}

A) CABECERA:

Título: Boletín de la Asociación del Magisterio Público Riojano.

Lugar: Logroño. La Rioja.

B) DATACIÓN:

Cronología:

- Primer número: 1 de mayo de 1899.

- Ultimo número: 25 de abril de 1903.

- Suspensión: ninguna.

1. En el número 3 del Boletín de 1 de junio de 1899 aparece la lista de asociados con nombre, apellidos y lugar en el que ejercen el magisterio. 
Periodicidad:

- Mayo de 1899

Se publica los días 1 y 15 de cada mes.

- Noviembre de 1899 Se publica los días 5, 12, 20 y 28 de cada mes.

- Septiembre de 1900 Se publica los días 10, 20 y 30 de cada mes.

- Septiembre de 1901

- Julio de 1902 -

Abril de 1903 Se publica los sábados.

Se publica los días 10, 20 y 30 de cada mes.

Sede social:

Redacción: Calle General Vara de Rey, 4, 2․

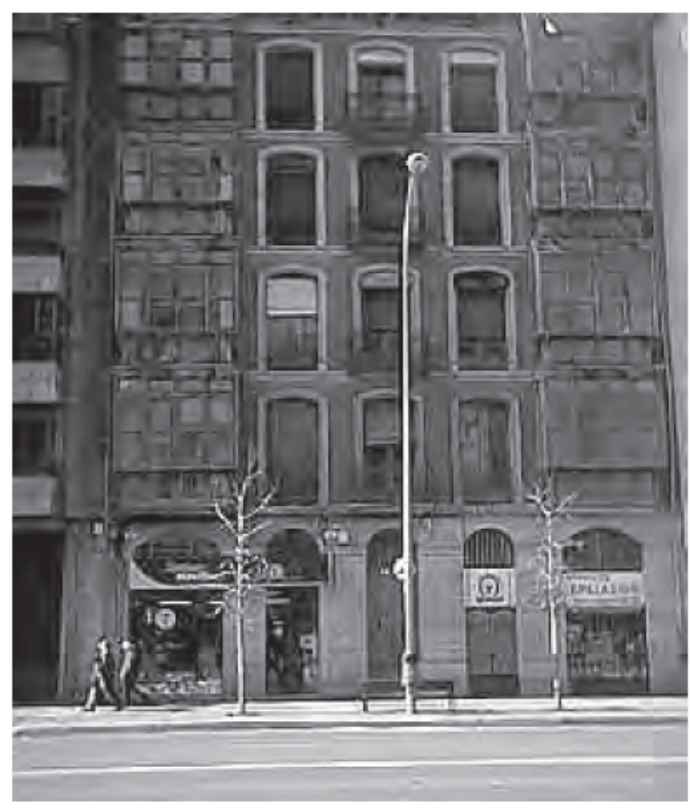

Figura 1. Fachada de la sede de la asociación.

Impresión: Imprenta Viuda de Venancio de Pablo, Mercado, 50.- Logroño, e Imprenta Moderna, Mercado,120 y Amós Salvador, 3.- Logroño.

\section{C) CARACTERÍSTICAS TÉCNICAS:}

\section{Formato:}

- Páginas: desde el inicio de su publicación hasta el 26 de julio de 1902 el boletín tiene 4 páginas de 320 × $220 \mathrm{~mm}$. Posteriormente son 8 y en algunas ocasiones 12 con formato de $220 \times 160 \mathrm{~mm}$.

- Columnas: Son dos de 110 mm. de anchura. 


\section{Estructura:}

- Ilustraciones: No posee.

- Secciones: Cuenta con tres secciones fijas:

1. Sección Oficial, para informar a los socios de todas las disposiciones oficiales que sean de interés.

2. Sección Doctrinal, con la que se pretende proporcionar los medios que impriman a la enseñanza escolar un carácter de aplicación, dándole a todas las materias pedagógicas un sentido práctico.

3. Sección Noticias, donde se informa sobre las vacantes, los nuevos socios que se incorporan a la asociación, traslados, donativos, nombramientos, defunciones, quejas, advertencias, ofrecimientos, premios, aclaraciones... Además de estas secciones se incluyen, en algunos números, el estado de cuentas de la sociedad; el almanaque del maestro, con los días festivos del mes y la correspondencia que había sido recibida, contestada o pendiente de contestar por parte de la asociación a sus miembros...

- Folletines: a lo largo de varios números se publica en la sección doctrinal una serie de artículos sobre los diferentes sistemas de educación pública seguidos en los pueblos más notables, tanto de los tiempos antiguos como de los modernos: Grecia, Roma...

Con esta serie de artículos perseguían 3 objetivos:

$1^{\circ}$. Hacer una reseña de las principales escuelas pedagógicas.

$2^{\circ}$. Exponer los defectos de cada una.

3‥ Hacer aplicación de sus principios en las escuelas primarias.

\section{Ficha Analítica}

\section{D) EMPRESA PERIODÍSTICA}

\section{Aspectos Económicos:}

- Lugar de Suscripción: en la sede de la Asociación.

- Precio de Publicación: la suscripción era de 2 pesetas anuales, pasando a 3 pesetas en años posteriores y era obligatoria para todos los asociados. El pago se realizaba en la sección territorial a la que se pertenecía; tales secciones eran 9, que se correspondían con las cabeceras de comarca de La Rioja $^{2}$ que, a su vez, englobaban una serie de pueblos próximos.

2. Las comarcas riojanas tienen rasgos muy diferenciados; según datos censales de 1900, se localiza la siguiente caracterización demográfica: la Tierra de Cameros está integrada por municipios exclusivamente rurales, muy pequeños, donde el más importante es Torrecilla de Cameros (1.545 habitantes). En la Rioja Alta las poblaciones más destacadas son Nájera (2.836 habitantes), Santo Domingo de la Calzada y Haro (7.914 habitantes). La Rioja Baja alberga los municipios más poblados, como Calahorra (9.475 habitantes), Arnedo (4.341 habitantes), Alfaro 


\section{E) EQUIPO DE REDACCION:}

\section{Dirección:}

- Director: D. Esteban Oca, presidente de la Asociación. El artículo 45 del Reglamento dice: "Será director del Boletín el Presidente de la asociación". Se mantuvo en el cargo durante los 5 años de vida del Boletín.

\section{Redacción:}

- Redactores: El equipo de redacción estaba formado por 12 redactores, 8 delegados de las 8 cabeceras de comarca de la Rioja y 4 delegados de la capital de la provincia.

En números sucesivos se prescindió de los redactores de Alfaro y Cervera del Río Alhama y posteriormente se sustituyeron dos maestros de la capital riojana por dos delegados de Lardero, un pueblo pequeño de la comarca de Logroño.

Asimismo cada sección territorial contaba con su propia Junta directiva o Junta de Partido, formada por el Presidente, dos Vocales y el Secretario.

F) NATURALEZA:

\section{Finalidad:}

El Boletín pretende ser:

- uno de los medios de unión entre todos los socios, estrechando los lazos de compañerismo;

- un medio de ilustración y de transmisión de noticias;

- un medio de comunicación con las demás asociaciones provinciales y con todo el Magisterio de la Nación;

- un medio de relación con las demás Sociedades;

- un medio para hacer llegar a las autoridades las necesidades de la enseñanza;

- un medio para defender los derechos de los maestros;

- en definitiva, un medio para cumplir con todos los ideales de la Asociación.

\section{Características Educativas}

De la primera lectura del Boletín se constata que no sólo se pretende que sea una "gacetilla" de información legal o de noticias locales de los diferentes socios. Una somera lectura permite obtener información sobre cuales son las fuentes pedagógicas en las que se inspira y las relaciones que mantiene con las

(5.983habitantes) y Cervera del Río Alhama ( 5.930 habitantes). Situada en la orilla derecha del río Ebro, Logroño, capital de la provincia y de la región, (19.237 habitantes). 
autoridades académicas, especialmente con la Inspección Educativa. Esta mera interpretación, habitual en la sistematización histórica, se hace más patente con el análisis de contenido y con los procesos de categorización que hemos realizado con el Programa informático Atlas/ti, y que posteriormente se describen detenidamente. Señalamos en este apartado las percepciones de las fuentes pedagógicas que sustentan ideológicamente el Boletín y el Asociacionismo Riojano, que ratifican su vertiente regeneracionista, siguiendo el estilo telegráfico y esquemático que hemos realizado en los puntos anteriores.

Fuentes pedagógicas:

En los apartados señalados, a modo de muestreo, se señalan las fuentes siguientes como inspiración especial.

- Temas preferentes:

- La Instrucción Pública.

- Medios prácticos para el progreso de la agricultura con el fin de contribuir a la reconstitución de la riqueza en la Rioja.

- Los Sistemas de Educación en las distintas épocas.

- Formación de museos agrícolas en las escuelas.

- Paseos y excursiones escolares.

- Informaciones destacadas:

- Información sobre el Congreso pedagógico realizado en Burgos del que se resaltan las conclusiones.

- La prohibición de las jubilaciones por imposibilidad física, estableciendo las sustituciones (norma firmada por la Reina Regente María Cristina).

- Fiestas escolares en los pueblos, (pues un objetivo del Magisterio Público Riojano era desarrollar la cultura popular y promocionar la educación primaria en los pueblos).

- Fallecimiento en 1903 del Señor Sagasta en Madrid.

- Comentarios y polémicas con otras publicaciones periódicas:

- Destaca un artículo del Vicepresidente de la Junta directiva en el que manifiesta su indignación por un artículo publicado en la prensa alemana sobre el Magisterio Español, en el que se señalaba como culpable de la decadencia de España al Magisterio de primera enseñanza, al que consideraba poco instruido, carente de autoridad moral y poco considerado por parte de los poderes públicos; se contesta una por una a las acusaciones.

- Otra noticia del Boletín se centra en una nota publicada en El Siglo Futuro, periódico católico madrileño, sobre la situación que se estaba dando en la Escuela Normal de Maestras de Vitoria, donde se dejaron de dar cla- 
ses por falta de personal, y donde actuaban como profesoras quienes carecían de los títulos reglamentarios.

- También se hacen numerosas referencias a vacantes y decretos publicados en la Gaceta de Madrid. ${ }^{3}$

- Además aparecen en varios números del "Boletín" noticias publicadas en el diario La Rioja, fundado en 1889 y que sigue publicándose en la actualidad siendo el diario de noticias más importante de la provincia, en el que se reseña, entre otras actividades regeneracionistas fomentadas por la Asociación, la Fiesta del Árbol acontecida en varios pueblos y en la capital.

\section{Relaciones con la Inspección Educativa}

En el Boletín del Magisterio Público Riojano no aparece de manera explícita cuales son las relaciones de la Asociación con la Inspección de Educación, pero sí se deduce, de las notas escritas en algunos de los ejemplares, que eran muy cordiales y afables, rozando casi el servilismo ante un superior; recuérdese que, en esos años, sólo había un Inspector de Educación en La Rioja y que sus visitas, por medios tradicionales y caballerías, solían durar uno o dos meses partiendo desde las oficinas de Logroño. En el primer número del Boletín, en un apartado denominado Saludos y visitas, aparece una nota relatando un encuentro entre la Junta directiva y el Inspector de Primera Enseñanza:

"La Junta Directiva tuvo el honor de ofrecer sus respetos al Señor Gobernador Civil de la provincia y al Señor Inspector de Primera Enseñanza. Ambas autoridades agradecieron la atención y en frases cariñosas estimularon a los maestros a seguir con la noble tarea de ennoblecer, ilustrar y trabajar por la cultura de los pueblos".

En otro número se avisa la llegada del nuevo inspector : "al fin se ha recibido en estas oficinas el título administrativo del Sr. D. José García Cons, que ha anunciado su llegada". También se recordaba desde el Boletín cuando el Inspector Provincial iba a realizar sus visitas a las escuelas de la provincia: "Estando próxima la visita del Señor Inspector de Primera Enseñanza, recomendamos a los Sres. Maestros se provean de los impresos necesarios para la visita" o "A fin de mes comenzará la visita de primavera a varias escuelas de la provincia".

3. La Gaceta de Madrid ha tenido una historia especial. En 1661 apareció en Madrid una gaceta con el nombre de Relación o gaceta de algunos particulares así políticos como militares y que recogía los avisos y noticias relativas a su título. Pronto se convirtió en un órgano de información de carácter oficioso y en 1697 cambió su nombre por el de Gaceta de Madrid. Esta publicación desde su inicio, fue periódica y no ocasional, como las que se estaban publicando en otras ciudades. En 1762, durante el reinado de Carlos III, por una Real Orden pasó a editarse con cargo al Estado, dos veces por semana, y a ser el órgano oficial del Gobierno; a partir de 1884 fue una publicación diaria. En 1936 cambió de nuevo de nombre para llamarse Boletín Oficial del Estado, que todavía conserva. 
Una relación entre cordial, chismosa y sumisa, donde las influencias de reforma quedaban supeditadas a la cordial comunicación burocrática y oficial.

\section{Patrocinio}

El Boletín de la Asociación del Magisterio Público Riojano no inserta publicidad en sus páginas hasta el número 106 -22 de febrero de 1902, en el cuarto año de publicación- cuando es patrocinado por dos Imprentas y Librerías de La Rioja, hasta el final de su publicación en 1903. Una de ellas es la Imprenta y Librería Viuda de Venancio de Pablo, situada en la plaza del Mercado 50 en la capital riojana. La otra es la Imprenta y Librería Moderna, con dos direcciones en la capital riojana: Salvador,3 y Mercado,120. La primera opta por una publicidad donde destaca los productos que se venden en la librería: surtido de libros, devocionarios, mesas, estuches, diplomas e incluso rosarios y medallas. La segunda insertaba en su publicidad las obras que tenían a la venta y al precio por el que se podían conseguir, como, por ejemplo, el Epítome de la Gramática de la Lengua Española, encartonado, escrito para niños, por Don Millán Orío y Rubio, al precio de 9 pesetas la docena.

Las obras anunciadas eran escolares para uso de alumnos y maestros, aunque también se ofrecían libros de tipo agrícola y ganadero (desde el Boletín se daban sugerencias para el progreso de la agricultura, con el objetivo de contribuir a la reconstitución de la riqueza en la Rioja). Libros, como, por ejemplo:

- Tratado práctico de la cría del conejo doméstico, de Martorell, al precio de 1,25 pesetas.

- El Almendro, (su vegetación, multiplicación, injerto), por Mariano Vallés, a 3 pesetas el ejemplar.

Cuando el anuncio era muy extenso, ocupaba toda la página, el número de éstas aumentaba, pasaba a ser de 12 en lugar de 8 páginas.

En lo referente a la impresión del Boletín, se encargaron las dos Imprentas mencionadas ${ }^{4}$. Durante algo más de tres años los gastos corrían a cargo de la Asociación; en el cuarto año de publicación, concretamente desde el número 126 (26 de julio de 1902), se editó en Viuda de Venancio de Pablo; a partir de esta fecha se imprimió en Imprenta Moderna, ya que los propietarios de ésta se ofrecieron a publicar gratis tres números mensuales del Boletín de la Asociación que, en ese momento, se publicaba los días 5, 15 y 25 de cada mes; este gracioso patrocinio permitió que no se exigiese cuota alguna a los socios durante el año, en vista del buen estado de fondos de la Sociedad. Los fondos de la Asociación en esa fecha eran boyantes, dentro de la simplicidad gestora y de los fondos obtenidos: se reclamaba, para ingresar en la Asociación, una cuota de inscripción de una peseta y otras dos en concepto de suscripción del primer año

4. En la última página de cada ejemplar aparece la Imprenta que lo ha editado. 
al periódico; incluso emplearon mil pesetas en la adquisición de obras pedagógicas y didácticas ampliando así la biblioteca de la Asociación, cuyas obras eran solicitadas y consultadas por los socios. A continuación se muestra un ejemplo de la propaganda que estas dos librerías logroñesas insertaban en el Boletín de la Asociación.

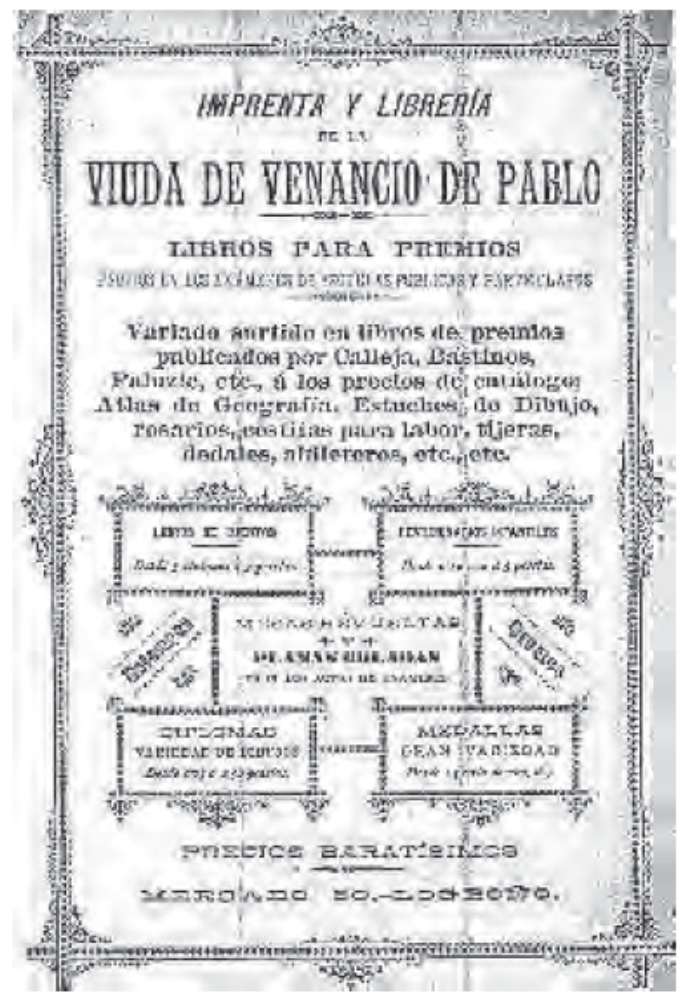

Figura 2. Ejemplo de publicidad en el Boletín de la Asociación.

\section{Análisis de contenido del Boletín de la Asociación}

Tomando la publicación como universo y síntesis de las tendencias y actividades educativas, hemos realizado una investigación sobre el contenido del Boletín de la Asociación del Magisterio Público Riojano, a través de una metodología cualitativa que permite comprender, no sólo la temática abordada, sino fundamentalmente el entramado de significados y relaciones reflejados en la publicación, su finalidad y el contexto socio-político-educativo en que se desarrolló.

Para realizar este estudio nos hemos basado en los principios de la Teoría Fundamentada, de carácter inductivo y gran aplicación en el ámbito de las Ciencias Sociales, y en el programa Atlas/ti, proceso que se describe seguidamente. 


\section{Temas básicos de estudio pedagógico}

Sin extendernos en las múltiples definiciones y perspectivas desde las que se puede iniciar el análisis de contenido, destacamos algunas características importantes de esta metodología, como la diversidad de métodos y técnicas cuantitativas y cualitativas que permite aplicar, la preocupación por la objetividad y sistematicidad en los procesos, la doble finalidad implícita en los análisis, el proceso para descubrir y describir realidades, la posibilidad de localización de los significados ocultos $y$, finalmente, la relevancia de los procesos de inferencia para generar conocimiento, "razón de ser de todo análisis de contenido" (Krippenpendorff, 1997). Efectivamente, los procedimientos inductivos servirán para explorar ciertos supuestos teóricos que, en este estudio concreto, son los relativos a la influencia del Boletín como iniciativa del magisterio riojano para mejorar la educación y transformar la sociedad de finales del siglo XIX y principios del XX.

En la Fig. 3, se puede apreciar el diseño de nuestro estudio.

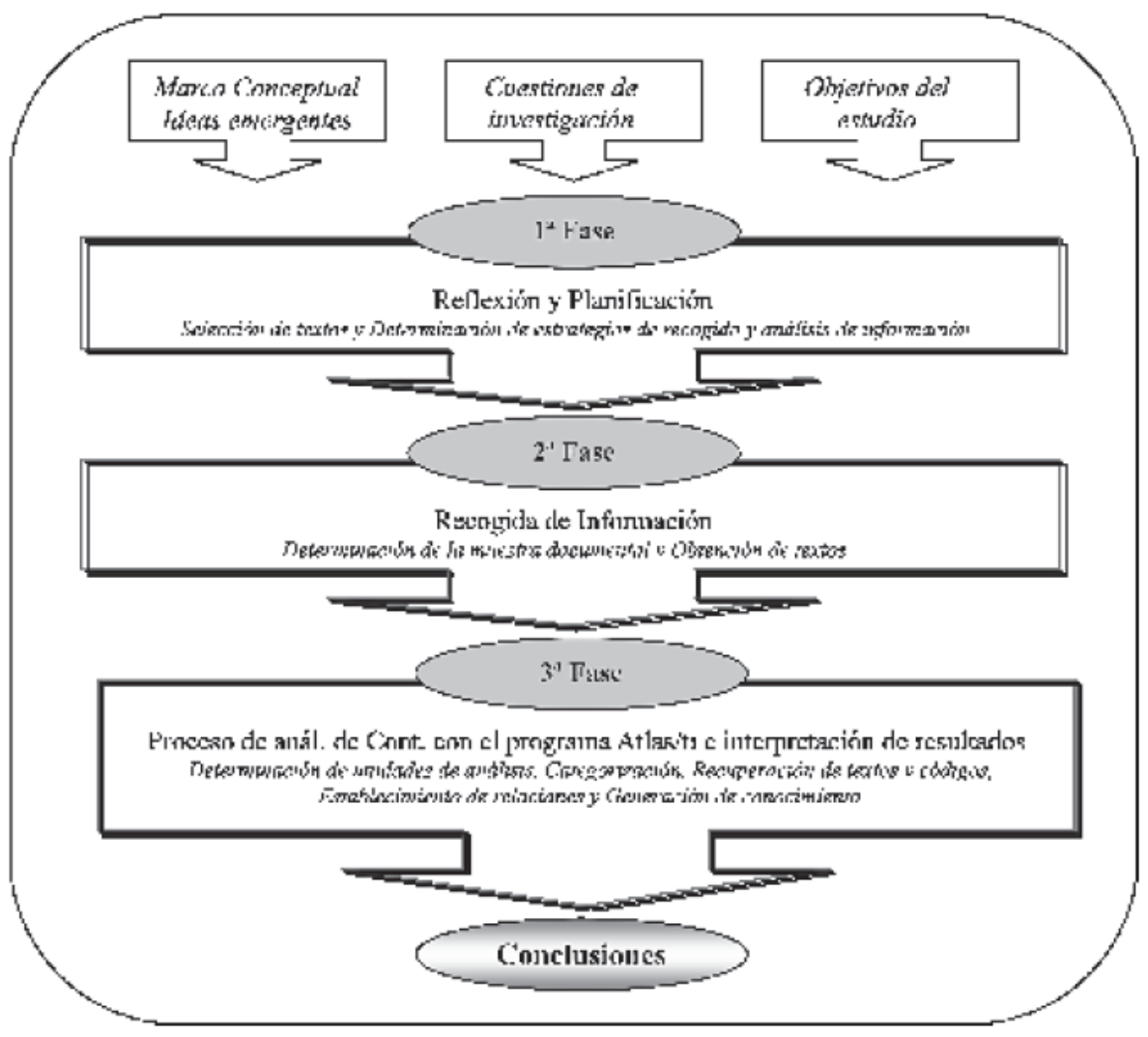

Figura 3. Diseño del Estudio. 


\section{Marco conceptual}

Respecto al marco conceptual, nuestro análisis de contenido se apoya en los principios de la Teoría Fundamentada (Grounded Theory), de gran aplicación en investigaciones cualitativas en el ámbito de las Ciencias Sociales, preocupadas no sólo por la descripción comprensiva, sino también por la explicación de los datos recogidos en la realidad, es decir, por la generación de nuevos conocimientos (las categorías que se establecen), en torno a las cuestiones de investigación.

La Teoría Fundamentada se concentra en la determinación de una categoría central o fenómeno, en términos de las causas, que hacen que emerja el contexto en el que se da dicho fenómeno, las estrategias por las cuáles evoluciona y las consecuencias de dichas estrategias. De este modo, orientamos el descubrimiento de patrones de hechos: bajo ciertas condiciones suceden ciertos acontecimientos.

En nuestro estudio sobre el contenido del Boletín, decidimos, entre otras muchas posibilidades de focalización, priorizar la atención del estudio en un fenómeno: contribución de la Asociación y de sus iniciativas hacia la mejora de la enseñanza. Efectivamente, como veremos, el Boletín y la Asociación que lo sustenta, supone una iniciativa más a favor de la regeneración y el cambio educativo, tan demandados en el período histórico en el que surge y en el que se buscaba, al menos teóricamente, el progreso social y la transformación de España a través de la instrucción. Desde esta perspectiva, considerábamos además que los procesos de mejora educativa se desarrollan en un sistema social de intercambios entre individuos e instituciones, de modo que el Boletín podía constituir un centro de referencia en dicho sistema social.

\section{Cuestiones de investigación en el análisis de contenido}

Inicialmente nos planteamos diversas cuestiones sobre el Boletín:

- ¿Cuáles son los temas predominantes en el Boletín? ¿Se corresponden con su finalidad?

- ¿Cómo contribuye el Boletín a la mejora educativa, a la introducción de cambios en el ámbito educativo? ¿cuál es su capacidad para transformar la realidad?

- ¿Cuáles son los problemas, expectativas o demandas que desembocan en esa necesidad de mejorar la educación?, (condiciones causales)

- ¿Cuáles son los mecanismos que se establecen para promover dicha mejora? (estrategias).

- ¿Quién considera el Boletín que debe ser el centro o pivote de dicha transformación educativa? (estrategias).

- ¿Se corresponden las directrices oficiales con las demandas de los maestros? 


\section{Objetivos y Supuestos del estudio}

Teniendo en cuenta que el Objetivo General de nuestro estudio es el de describir y explicar las contribuciones educativas del Boletín de la Asociación del Magisterio Riojano en el período histórico en que se desarrolló, para dar respuesta a los interrogantes previos, nos planteamos los siguientes Objetivos:

- Elaborar un esquema teórico explicativo del papel del Boletín en la introducción de mejoras educativas en el contexto socio-político-educativo de la época, por lo que nos propusimos determinar las condiciones causales del cambio educativo o, expresado de otra forma, localizar las estrategias desarrolladas, los aspectos facilitadores u obstáculos y las consecuencias de tales estrategias.

- Patentizar la relevancia del Boletín como medio para estimular la "profesionalización del maestro", esto es, resaltar la mejora de la formación inicial.

- Analizar la relación entre los principios ideológico-políticos de ese período histórico y la profesionalización de los maestros riojanos en particular y del magisterio español en general.

En congruencia con los objetivos indicados, se plantearon algunas hipótesis o supuestos de comprobación:

- El Boletín constituye una iniciativa para mejorar la educación difundiendo ideas regeneracionistas de los intelectuales y políticos de la época.

- El Boletín centra su atención en el maestro, convirtiéndole en el promotor de dicha mejora, fomentando su profesionalización.

- El Boletín señala los principales problemas, demandas del magisterio, así como los obstáculos para desarrollar las reformas educativas.

- El Boletín constituye un medio difusor de las reformas, (incluidas las propuestas legislativas) y las "estrategias" del magisterio de la época para promover la mejora educativa.

\section{Fases}

Según el diseño expuesto en la Fig. 3, se procedió al desarrollo del estudio.

1a Fase: Selección de textos y Determinación de estrategias de recogida y análisis de la información.

En esta fase llevamos a cabo la planificación de nuestro análisis de contenido desde la localización de los números que se conservan del Boletín de la Asociación del Magisterio público Riojano en la Hemeroteca Municipal de Madrid y en el Instituto de Estudios Riojanos, de Logroño, las revisiones teóricas sobre el contexto socio-educativo de la época y el contraste con investigaciones similares con otras publicaciones, hasta la adopción de decisiones sobre la metodología concreta de análisis de contenido que íbamos a abordar. 
Una decisión fundamental en esta fase fue la adopción del programa informático ATLAS/ti como herramienta de análisis de contenido, dadas sus posibilidades metodológicas. Este programa, desarrollado en el contexto de un proyecto de investigación interdisciplinar de la Technical University of Berlin entre informáticos, psicólogos y lingüistas, fue desarrollado por Thomas Muhr, profesor en dicha Universidad, y comercializado desde 1993. Se trata de un programa de análisis de datos cualitativo aplicado en diversos ámbitos, (Educación, Ciencias Sociales, Medicina, Investigaciones de mercado, Planificación, etc.), que, además de permitir la localización y recuperación de datos, facilita el establecimiento de relaciones entre los diversos elementos para hacer explícitas las interpretaciones y, en un momento dado, extraer otros nuevos que puedan apoyar argumentos o conclusiones del investigador. De este modo, se abre un "contexto de descubrimiento", o ventana, donde se pueden representar diversos "mapas conceptuales" construidos a partir de la información de los textos, para explorar datos y estructuras implicadas, cuyos resultados cabe reflejar en otros textos, diagramas u otros medios de representación y comunicación.

\section{2aㅡ Fase: Determinación de la muestra documental y Obtención de datos.}

\section{Descripción de la Muestra de Boletines}

En nuestro estudio, los boletines constituían las unidades de muestreo. A partir del universo (150 números), seleccionamos como muestra un $10 \%$ del total, esto es, 15 boletines. Para garantizar la presencia en nuestra muestra de números correspondientes a cada uno de los cinco años de vida del Boletín, (fundamental para estudiar su evolución), realizamos un muestreo aleatorio estratificado por años (en función del número de boletines publicados cada año) $)^{5}$. A esta muestra, le añadimos "intencionalmente" el primer boletín, ( $n^{\circ}$ 1), dada la posibilidad de obtener información relativa a la creación del Boletín, opiniones sobre sus fines, etc, de modo que se obtuvo una muestra de 16 boletines distribuidos de la siguiente forma -Figuras 4 y $5-$ :

\begin{tabular}{|c|c|c|c|c|c|}
\hline Alis & 1899 & 1900 & 1901 & 1902 & 1903 \\
\hline \multirow{2}{*}{$\begin{array}{l}N^{0} \text { bulelines } \\
\text { publicados }\end{array}$} & 20 & 40 & 38 & 39 & 13 \\
\hline & $\begin{array}{l}\mathrm{ri}^{\circ} 1 \text { ul } \\
\mathrm{n}^{\leq 1} 20\end{array}$ & $\begin{array}{l}\mathrm{n}^{\circ} 21 \text { ul } \\
\mathrm{n}^{*} \mathrm{EO}\end{array}$ & $\begin{array}{c}n^{\circ} 61 \text { ш } \\
n^{\prime 9} 98\end{array}$ & $\begin{array}{l}\mathrm{n}^{\circ} 99 \text { 니 } \\
\pi^{13} 138\end{array}$ & $\begin{array}{c}\text { ri }^{\circ} 139 \text { sl } \\
\text { n" } 1.51\end{array}$ \\
\hline $\begin{array}{l}\mathrm{N}^{n} \text { de Boletines } \\
\text { selexciunados }\end{array}$ & 3 & 4 & 4 & 4 & 1 \\
\hline Polctines & $\begin{array}{l}n^{n 1}: n^{n 9} \\
n^{\circ} 18\end{array}$ & $\begin{array}{l}N^{\circ} 21, n " 2,3 \\
n^{\circ} 29, n^{\circ} 47\end{array}$ & $\begin{array}{l}\mathrm{k}^{\circ} 61, n^{\prime \prime} 73 \\
n^{2} 89, \mathrm{n}^{\circ} 58\end{array}$ & $\begin{array}{l}n^{n} 101, n^{*} 109 \\
n^{0} 133, n^{3} 137\end{array}$ & $n^{n} 150$ \\
\hline
\end{tabular}

Figura 4. Distribución de boletines.

5. El número específico de boletines seleccionados por año se calculaba multiplicando la proporción de boletines de cada año o estrato, por el tamaño de la muestra, $(n=15)$. Así obtuvimos un error típico de la muestra aleatoria estratificada proporcional de 0.12 . 


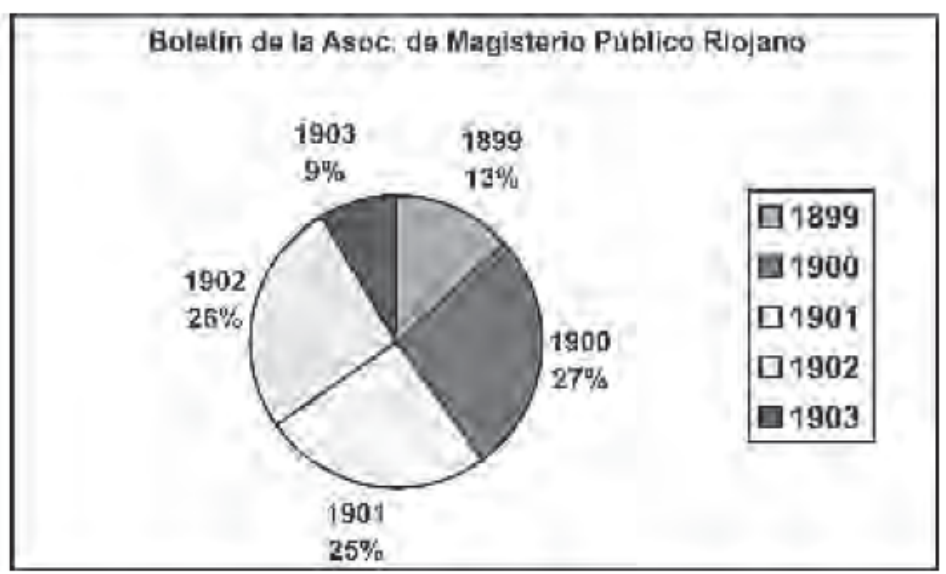

Figura 5. Porcentaje de boletines en la muestra, por años.

\section{Obtención de Datos}

Una vez determinada la muestra de boletines, los convertimos en documentos primarios que el programa Atlas/ti pueda manejar. Para ello, transformamos los microfilms en que estaban recogidos los boletines en fotocopias que pasamos a escanear y almacenar en formato de "Solo texto". Obtuvimos así un total de 45.648 palabras.

\section{3a Fase: Proceso de análisis de contenido con el programa Atlas/ti e interpretación de los resultados.}

Al igual que otros autores, (Miles y Huberman, 1994; Gil Flores, 1994), consideramos que las fases de análisis e interpretación de datos no deben considerarse como entidades separadas, pues ello excluiría la posibilidad de recoger nuevos datos para completar interpretaciones o comprobar nuevas hipótesis que surgen a menudo a lo largo de todo el proceso en las investigaciones cualitativas; incluso el propio Atlas/ti funciona a tres niveles de trabajo interrelacionados, de modo que, en cualquier momento, se puede pasar de uno a otro, según la interpretación del investigador. Nos referimos a un nivel organizacional, de preparación de los documentos que vamos a analizar, (nuestro "corpus textual"), a un nivel textual, de segmentación de los textos, la asignación de códigos, creación de categorías, la escritura de reflexiones de investigación o memos ${ }^{6}$ etc. Y

6. Las "memos", abreviatura de memorándums, son anotaciones realizadas durante todo el proceso de investigación que recogen intuiciones, interrogantes, reflexiones, interpretaciones tentativas etc. que pueden ayudarnos a tomar decisiones de todo tipo, metodológicas, (memo metodológicas), refinar nuestra teoría, (memos teóricas), etc. El Atlas/ti permite además, en sus últimas versiones, considerarlas como códigos que a su vez pueden recuperarse, relacionarse, etc. 
finalmente, un nivel conceptual, en el que relacionamos los diversos códigos para formar redes semánticas o categorías más amplias y significativas.

En la Fig. 6 presentamos la secuencia de pasos genérica seguida en el análisis de contenido tal como se presenta en el manual del Atlas/ti, (Muhr, 1997). En la práctica puede alterarse el orden, repetir algún paso para profundizar en la información obtenida, etc.:

1. Crear un Proyecto de investigación (Unidad Hermeneútica).

2. Asociar todos los archivos de datos (Documentos Primarios).

3. Leer y seleccionar pasajes, (identificar áreas en los párrafos). Asignar Códigos o Memos a cada segmento de texto relevante, (Quotations).

4. Comparar segmentos textuales de igual/distinto significado. Asignar más archivos al proyecto.

5. Organizar los Documentos Primarios, Códigos y Memos utilizando "familias".

6. Construir redes semánticas, proposiciones o terminologías a partir de los códigos creados. Crear "Super-códigos", (categorías conceptuales amplias que resultan de la combinación-búsqueda de otras categorías o códigos), a partir de los cuáles generar "teorías emergentes".

7. Exportación de datos e informe de investigación.

Figura 6. Secuencia de pasos en el análisis de contenido con el Atlas/ti.

Determinación de las unidades de análisis, (Categorización), Recuperación de textos y códigos (Establecimiento de relaciones)

Adaptando a nuestro propio estudio la secuencia de pasos previa, llevamos a cabo diversos procesos de análisis de datos cualitativos, esto es, la determinación de las unidades de análisis de contenido, la creación de categorías, recuperación de textos y códigos vinculada al contraste de nuestras hipótesis y objetivos de investigación y el establecimiento de relaciones que, en conjunto, permitan formular interpretaciones propias o "teorías de bajo nivel".

En concreto, nosotros Ilevamos a cabo una división manual del texto en fragmentos o citas textuales, -unidades de contenido- que fueran sentencias o párrafos que reflejasen distintas ideas significativas respecto a nuestro fenómeno $\mathrm{u}$ objeto de estudio. De este modo, obtuvimos una distribución de citas por año que resultó ser bastante homogénea, aunque se puede apreciar una riqueza conceptual ligeramente más elevada en los boletines de los años 1900 y 1901, tal vez justificada por el mayor número de boletines que se publicaron esos años. Por otra parte, de todos los boletines que constituyeron nuestra muestra, los números 18 y 61 fueron los de mayor y menor densidad conceptual, respectivamente. 
Paralelamente a la división textual en citas, conforme se va leyendo la muestra seleccionada, fuimos elaborando una serie de códigos y categorías ${ }^{7}$, apoyándonos en las referencias teóricas y metodológicas de la Teoría Fundamentada y en las ideas emergentes de los propios textos. Por otra parte, una de las herramientas que nos ofrece el Atlas/ti para estructurar dichas categorías y encontrar categorías progresivamente más amplias que aglutinasen a las anteriores; es su agrupación en "Familias". De este modo el conjunto de categorías pertenecientes a una misma familia comparten algún atributo común.

Asumiendo que podríamos realizar múltiples clasificaciones de dichas categorías en función de los fines del análisis de contenido, distinguiremos dos tipos fundamentales, las categorías referidas al "Boletín" como publicación (contribución editorial) y las categorías sobre el contenido del Boletín referido al fenómeno de estudio (su contribución educativa).

\section{Categorías referidas al "Boletín" como publicación}

Como complemento, puramente descriptivo, añadimos a las categorías anteriores un pequeño conjunto de categorías referidas a aspectos formales del boletín, como su estructuración en Secciones y Sub-secciones. A continuación calculamos las frecuencias de dichas categorías para valorar la importancia cuantitativa de determinados temas.

Hemos de señalar que no había una distinción clara y unívoca entre las diversas secciones, a menudo solapadas, (y paralelamente con las sub-secciones), ya que, aunque el contenido se refiriera a lo mismo, encontrábamos diversos títulos incluso con un tipo y tamaño de letra distinto. Por ello, la sección denominada Introducción a veces podría confundirse con la Doctrinal; por ej., el Boletín comenzaba directamente con este tipo de aspectos, o con la Oficial si lo hacía con alguna circular o información relativa a la Asociación de Magisterio Riojano. En cualquier caso, sí se puede destacar que la mayor parte de los boletines se dedicaban a la transmisión de noticias, y en su primera página presentaban el tema central a considerar en el boletín normalmente referido a aspectos "oficiales", legislación, (aunque sólo se la define como tal sección en el Boletín) y en menor medida a crónica de actividades, correspondencia o artículos firmados.

Los boletines, observando las subsecciones, transmitían información directamente dirigida a los maestros riojanos, referida a aspectos administrativos como los Derechos Pasivos del Magisterio; la provisión de plazas; nombra-

7. Aunque en el Atlas/ti se distinguen los códigos (conceptos que representan algún nivel de abstracción) de las categorías, vinculadas a búsquedas, (etiquetas correspondientes a fragmentos de texto recuperados en procedimientos de búsqueda complejos), nosotros hablaremos de categorías para referirnos a ambos, dado que asignamos códigos siguiendo el criterio de riqueza conceptual. 
mientos; matrícula en las normales; oposiciones; explicación detenida de los aspectos referidos a la legislación, (exposición de Reales Decretos, Órdenes, etc... con sus correspondientes implicaciones para el maestro); diversos asuntos relativos a la vida de los socios (defunciones, saludos y visitas, ...); transmitían informaciones sobre las actividades que como tal Asociación realizaban, como "La fiesta del árbol", "Biblioteca" "Resumen de acuerdos" de la Asociación; informaciones sobre otras personas o entidades importantes en el ámbito educativo (como, por ejemplo, las asociaciones de magisterio gerundense y madrileña o la inspección, e incluso alguna muestra de contenidos educativos como la subsección referida a "Sistemas Educativos").

La representación gráfica de la familia de secciones y la familia de subsecciones que realizamos con ayuda del Atlas/ti permite apreciar además las relaciones entre ellas: "estar asociado" (==), ser parte de (\{\}), "es a" (isa), "es propiedad de" (*\}) o "es causa de" (fi), como se representa en las figuras 7 y 8.

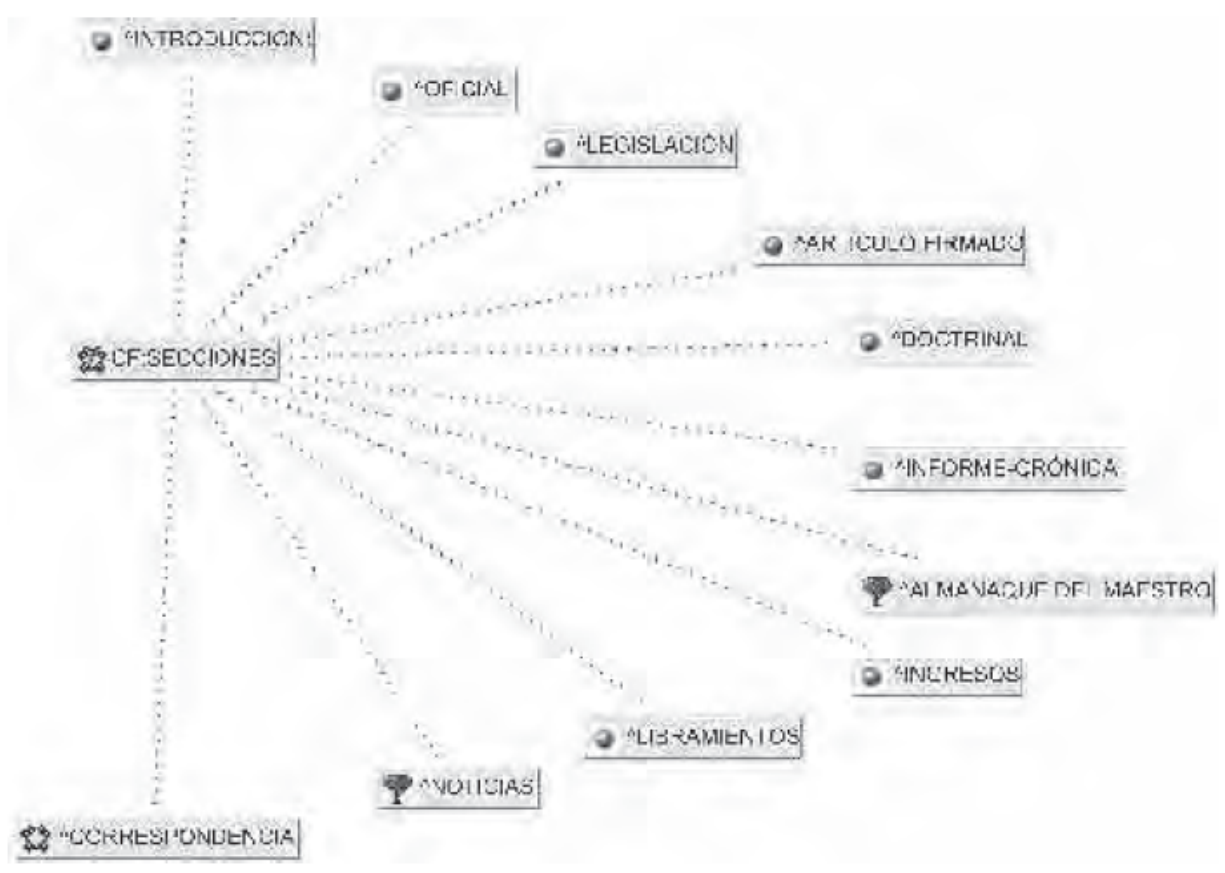

Figura 7. Familia de Secciones. 


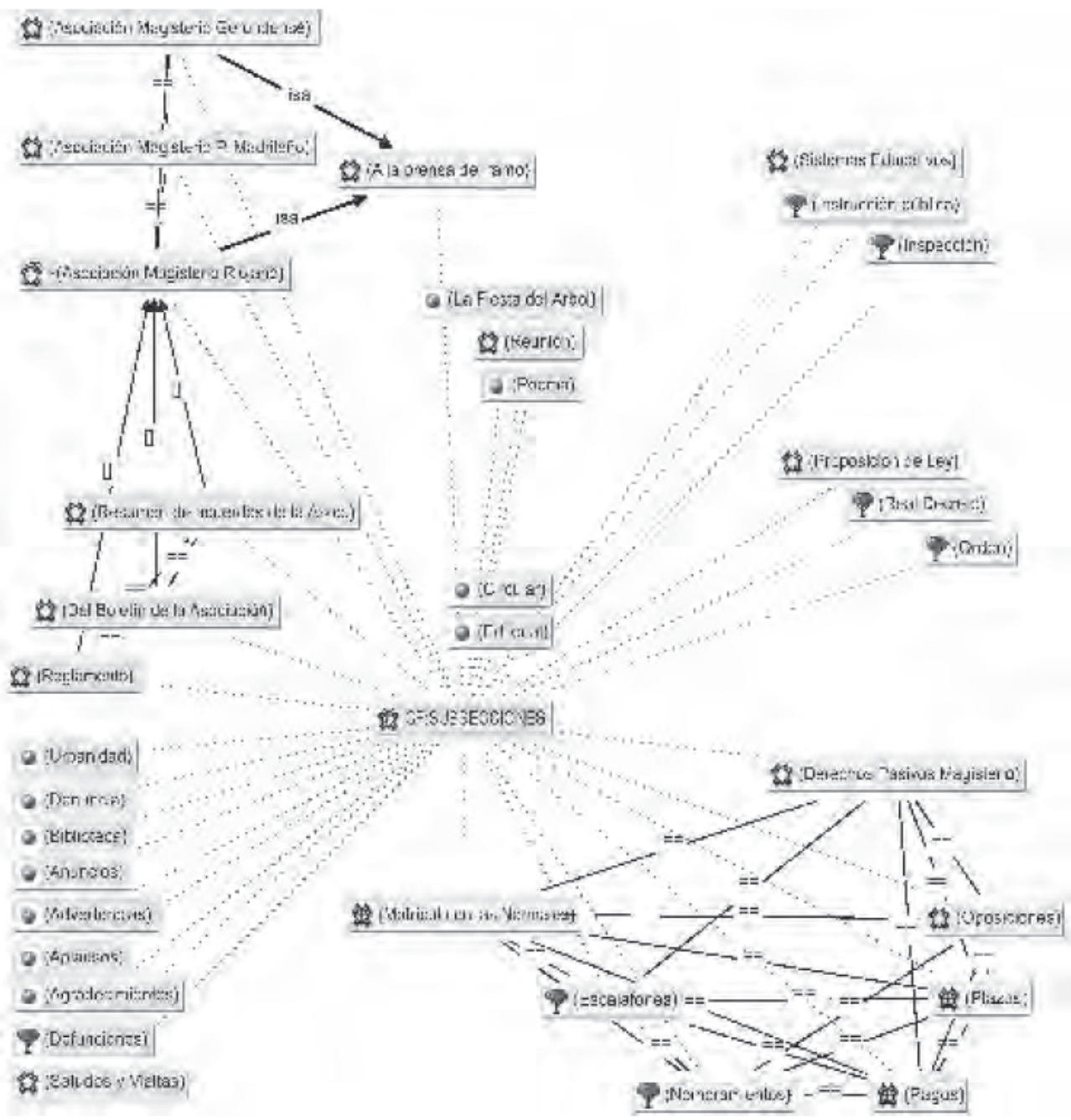

Figura 8. Familia de Sub-Secciones.

Respecto a las categorías referidas al Boletín como publicación, como se puede constatar en la Fig. 9, se refieren fundamentalmente a dos aspectos: los fines y los recursos del propio Boletín. Los "Fines de la Asociación", origen de los propios "Fines del Boletín" y, éstos, a su vez, originan la "Comunicación con otras publicaciones". Por su parte, "Los recursos del Boletín" son los responsables, tanto de su "Formato" como de su "Periodicidad"; de hecho, como indicamos anteriormente, cuando una imprenta se ofreció a publicarlo gratuitamente, aumentaron el número de boletines publicados por mes. 


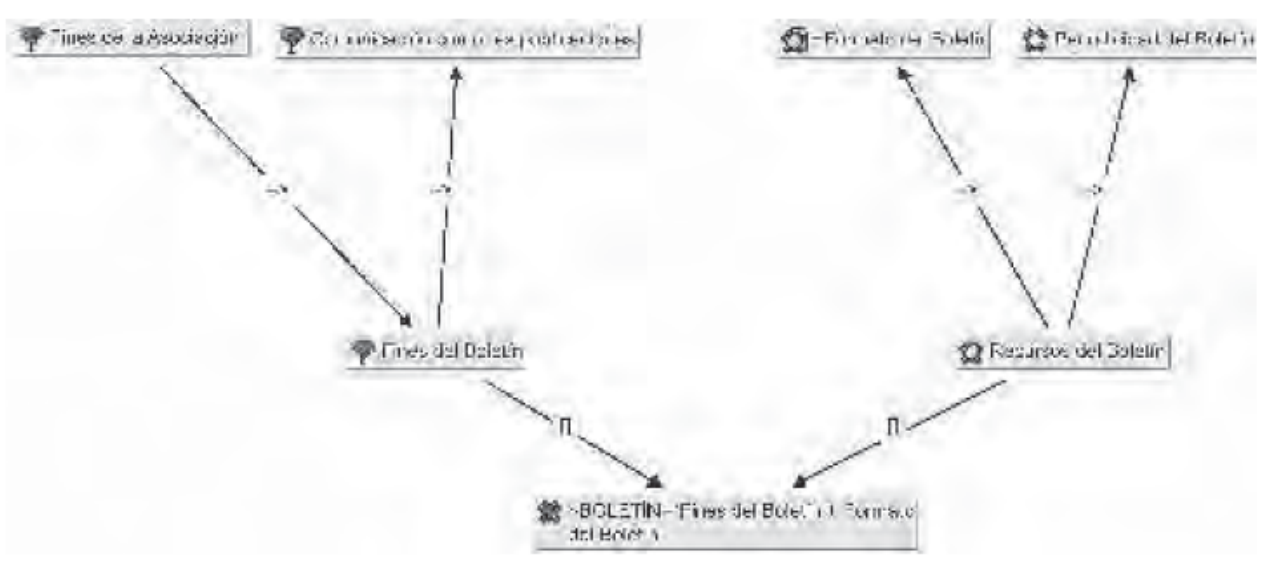

Figura 9. Categorías sobre el Boletín.

Categorías sobre el contenido del Boletín referido al fenómeno de estudio (su contribución educativa)

Tal vez la aportación más interesante de los análisis de contenido basados en la Teoría Fundamentada sea precisamente, superar la mera descripción de los fenómenos reflejados en los textos para generar pequeñas teorías de bajo nivel o interpretaciones, "fundamentadas" en las relaciones y propiedades de las categorías vinculadas conceptualmente con dichos textos. Como indicamos anteriormente, para generar nuestra propia interpretación, durante la lectura y análisis del contenido de los boletines fuimos elaborando un sistema de categorías propio centrado en el fenómeno que deseábamos estudiar. Por tanto, siguiendo la Teoría Fundamentada, creamos un sistema de categorías explicativas del fenómeno que deseábamos analizar, desde niveles inferiores puramente descriptivos, a menudo definidos en los términos en que aparecían en los textos, "codificación en vivo", a otros superiores de mayor carga conceptual relativas a las causas que provocan esa contribución, al contexto en el que surge la contribución del Boletín, el conjunto específico de condiciones dentro de las cuáles se desarrollan las estrategias para responder al fenómeno y las consecuencias de las mismas. Así, nuestro modelo de causascontexto-estrategias-consecuencias quedó definido a partir de las siguientes categorías señaladas en la figura 10: 
EL REGENERACIONISMO EDUCATIVO EN LA RIOJA Y LA ASOCIACIÓN DE MAESTROS...

\begin{tabular}{|c|c|}
\hline \multicolumn{2}{|c|}{ 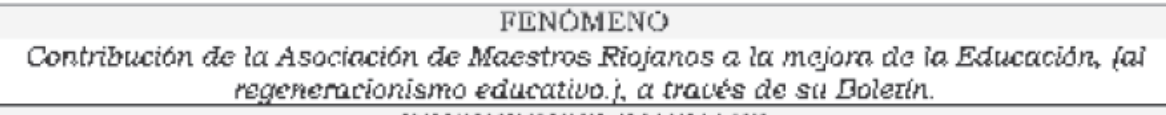 } \\
\hline \multicolumn{2}{|c|}{$\begin{array}{l}\text { CONIMCIONFIS CAUSA I.FS } \\
\text { Problemas organizativa - institucionales percibidos como necesidaries insarisfechas }\end{array}$} \\
\hline \multicolumn{2}{|c|}{ 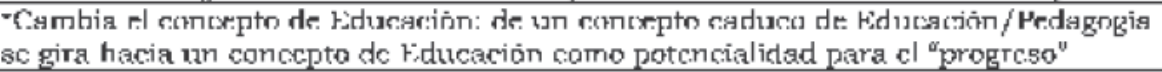 } \\
\hline 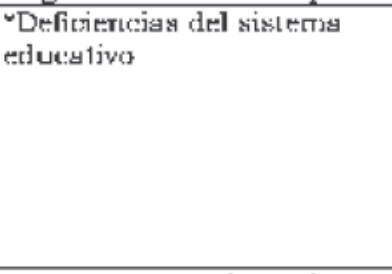 & 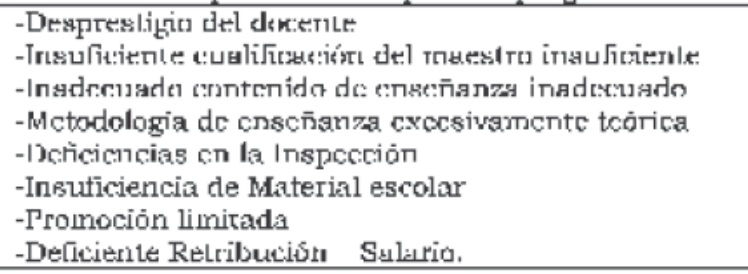 \\
\hline \multicolumn{2}{|l|}{ "T.cgislación inadccuada } \\
\hline \multicolumn{2}{|c|}{$\begin{array}{l}\text { "Re1.ragu Cullural } \\
\text { "Conciencia de fracaso }{ }^{*} \text { nacional }\end{array}$} \\
\hline \multicolumn{2}{|c|}{ *Poductividad cconónica insuficicintc } \\
\hline \\
\hline \multicolumn{2}{|c|}{ 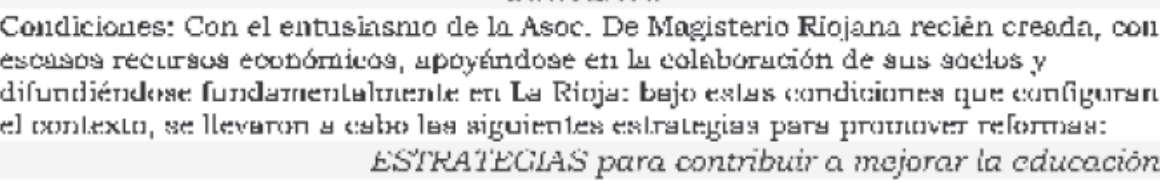 } \\
\hline $\begin{array}{l}\text { "Tortalecer la. "Clase del } \\
\text { Meudistecio" }\end{array}$ & 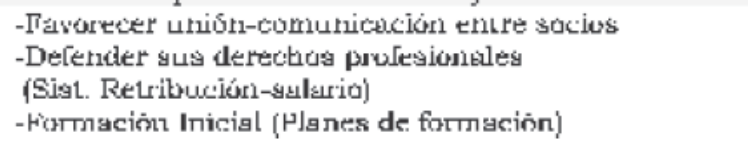 \\
\hline \multirow{3}{*}{$\begin{array}{l}\text { Establecer canales de } \\
\text { discustón pura promover } \\
\text { refunrus tedursulivas }\end{array}$} & $\begin{array}{l}\text { Instinuciones: Ayuntamiento, Ministerio, } \\
\text { Estado-unloridetes }\end{array}$ \\
\hline & $\begin{array}{l}\text {-Colectivos: Asoc. Mag. Madilieño, Asoc. Mag. } \\
\text { Gerundense }\end{array}$ \\
\hline & -Comunicación con otras publicaciones \\
\hline "Torlalecer infruestructurets & 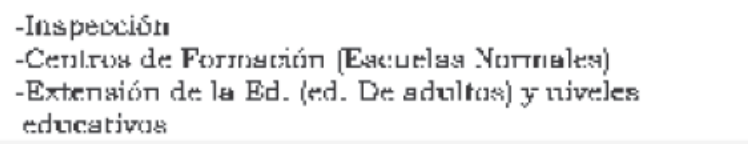 \\
\hline \multicolumn{2}{|c|}{ 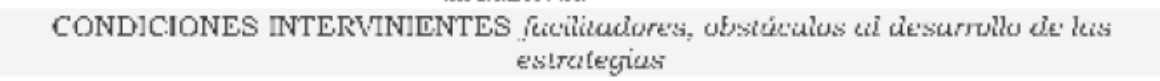 } \\
\hline \multicolumn{2}{|c|}{ PFortalezes } \\
\hline \multicolumn{2}{|c|}{ "Obstáculos } \\
\hline \multicolumn{2}{|c|}{ 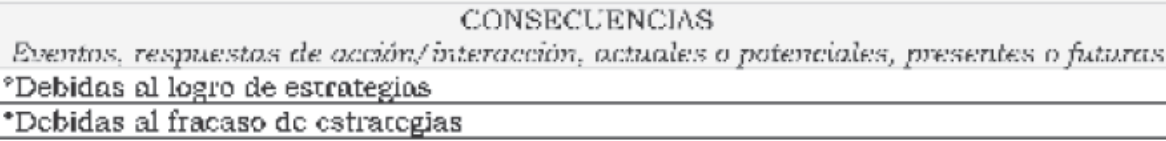 } \\
\hline
\end{tabular}

Figura 10. Modelo teórico explicativo. 
Se puede concluir que los textos de los boletines "reflejaban gran diversidad temática. Por supuesto, el tema prevalente, el centro temático del Boletín, era el Magisterio Español, y dentro de éste, el Magisterio Riojano". Como detalle curioso, en el que más tarde profundizamos, cabe señalar cómo se resaltaba la entidad del Magisterio Riojano, con sus características peculiares, pero en ningún modo aislado de otras asociaciones de magisterio. Es decir, sin negar el protagonismo del Magisterio Riojano como entidad relevante en sí misma, se la concebía totalmente relacionada con otras asociaciones similares, de modo que la cantidad de referencias a los maestros riojanos se aproxima a las referencias hacia los maestros en general. Podríamos pensar, al menos en este estadio de la investigación, que el Boletín se dirigía a los maestros riojanos, pero deseaba ir más allá de ellos mismos, ofreciendo y recogiendo informaciones sobre los maestros "en general", tal vez para fomentar con ello la conciencia de unidad como "clase de magisterio".

Curiosamente, vemos que la legislación educativa, pareció convertirse en el segundo protagonista del boletín, ya fuesen textos legislativos literales, comentarios a los mismos e incluso argumentaciones sobre la situación del magisterio basadas en leyes que se consideraban inadecuadas.

Destacamos también la abundancia de citas referidas a la Fiesta del Árbol, que podemos considerar un tema fundamental del Boletín, estrechamente vinculado a la necesidad de reformas y los sentimientos de regeneración.

Aspectos como las demandas del magisterio y, en particular, los problemas referidos al sistema de retribución de los maestros y sus salarios parecen ser atendidos ampliamente en nuestros boletines, así como las reformas educativas, fin al que se dirigían todos los esfuerzos del Boletín.

El resto de los temas, de menor extensión en el conjunto de los boletines analizados, podremos estudiarlos detenidamente viendo cómo se relacionan entre ellos a partir de nuestro modelo teórico explicativo particular.

Hemos creado las categorías, denominadas "super-códigos" (siguiendo la terminología del programa que estamos utilizando como herramienta de análisis), por combinación de códigos o categorías anteriores, a partir de ciertos procedimientos de búsqueda textual facilitados por el Atlas/ti. Fueron elaborados en función de las necesidades de que encontramos durante nuestros análisis: las categorías descriptivas, individuales aportaban ricos matices informativos, pero en algunos casos, era preciso aglutinar todas estas categorías individuales en una categoría superior o super-código, para tener una idea global sobre ciertos temas. Por ej., como veremos cuando contrastemos algunas hipótesis de trabajo, en ciertas ocasiones resultaba útil trabajar con una determinada asociación de magisterio, como la riojana, para estudiar sus peculiaridades; pero en otras ocasiones, era más importante considerar a todos los maestros, sin distinciones geográficas. En estos casos, fue precisa la generación de los super-códigos que presentamos en la Fig. 11: 


\begin{tabular}{|c|c|}
\hline SUPER-CÓDIGOS (Categorias resultantes de búsquedas) & $\begin{array}{l}\text { Fr. } \\
\text { citas }\end{array}$ \\
\hline MAESTROS (Asnc. De Magisterio y Magisterio Español) & 2.31 \\
\hline $\begin{array}{l}\text { DEFTCJENCLAS del SIST. ED.( "Retribución-Salario } \\
\text { deliciente", "Promoción limilada", "Maleriau escolar } \\
\text { insuficiente","Inspección deficiencias", "Metodologia enza. } \\
\text { excegivamente teōrica","Contenido enseñanza inguficiente" } \\
\text { "Cualificación del Maestro","Desarestigìn dẹl docente" }\end{array}$ & 152 \\
\hline $\begin{array}{l}\text { T.FGTSIACION (Tegsislación inadecuada, Tuegislación: } \\
\text { interpretación, Legislación: texto) }\end{array}$ & 137 \\
\hline $\begin{array}{l}\text { ASOCIACIONES MAGISTERIO ("gerundemse", "madrileña", } \\
\text { "riojana" }\end{array}$ & 121 \\
\hline *POLITICO= *Estado-autoridades-Miniaterio-Ayto. & 114 \\
\hline ARBOL = *arbol simboliza-Fiesta del ảrbol & 104 \\
\hline INSTITUCIONES= Mininistcrio, Estado-Autoridades, Ayto. & 104 \\
\hline CONDICIONES INTERVINIENTES (fortalezas, obstáculos) & 42 \\
\hline $\begin{array}{l}\text { FORTALECER LA "CLASE DEL MAGISTERIO" : "Fyvorecet } \\
\text { comunicación socios" , "Defender derechos profesionales" } \\
\text { "Formación inicial"] }\end{array}$ & 35 \\
\hline $\begin{array}{l}\text { FORTATJFCFR INFRAFSTRAFSTRUCTURAS ("Inspección", } \\
\text { "Cenlrus de Formuacionn") }\end{array}$ & 27 \\
\hline BOLETIN=*Fines de1 Boletin-Formalo-periodicidad-recursos & 16 \\
\hline JUSTIFICA="Justificación del fracaso y del éxito & 9 \\
\hline
\end{tabular}

Figura 11. Super-códigos.

Respecto a estos "super-códigos", debemos aclarar que el número de citas contenidas en los mismos es la suma del número de citas correspondientes a cada categoría concreta que forma parte de ellos. Por tanto, vemos de nuevo que la mayor abundancia de citas se asocia a los mismos temas que ya comentamos al presentar las categorías aisladas.

Finalmente, en este estudio descriptivo preliminar de las categorías, señalaremos algunos aspectos en relación a su evolución, y por tanto a la de los conceptos referidos a ellas a lo largo de los años en que se publicó el Boletín. El Atlas/ti nos permitía ver esta evolución analizando las categorías en función del boletín, y más concretamente del año en que se editó dicho boletín, incluyendo como criterio restrictivo en la búsqueda de las categorías, dicho año.

Generalmente, antes de seguir con los procesos de indagación, es preciso -conforme a las normas de investigación aplicada y a las recomendaciones del programa Atlas/ti- realizar una recopilación reflexiva de lo obtenido, esbozando algunas observaciones sobre los resultados. A partir de dichas tablas, y sin olvidar que trabajamos sobre una "muestra" de boletines, se obtuvieron datos que nos permitieron elaborar algunas interpretaciones inicia- 
les ${ }^{8}$ sobre los temas que se consideraron importantes en el boletín, esto es, ocuparon mayor extensión y $n^{\circ}$ de citas a lo largo de los años de esta publicación:

- Las referencias de contenido respecto al Boletín como publicación, se concentran, en el $1^{\text {er }}$. Año de su publicación, 1899 (9 citas 6 de las cuáles asociadas al no 1), lo cuál es lógico puesto que debía justificar su aparición, describir sus fines, organización, etc. En el resto de los boletines estudiados apenas sí encontramos, (1900, 1901 y 1902: 2 citas cada año), comentarios al progreso de esta publicación, incluidos los problemas económicos para sostenerla. Tal vez ello demuestre que lo importante para sus editores no era tanto convertirse en una publicación consolidada de gran difusión reclamando la atención continua de sus socios hacia el propio Boletín, como en difusión, con la sencillez de los medios de que disponían, a los temas educativos que consideraban verdaderamente importantes.

- Todos los aspectos que podríamos considerar políticos, agrupados en la categoría "Político", referidos a relación o mención de la asociación con diversas autoridades políticas, con los ministros encargados de la educación, las actuaciones ministeriales, el papel de los ayuntamientos en la mejora de la enseñanza, etc., parecen tener más relevancia durante los años 1900, (35 citas: concentradas sobre todo en el boletín no 21) y 1901, (32 citas: concentradas sobre todo en el boletín no 98), mientras que "decayeron" en el año 1902, (19 citas: prácticamente centradas en el boletín $n^{-101)}$ y por supuesto, en el último no del boletín donde sólo encontramos 2 citas.

- Las referencias de contenido relativas a la "Fiesta del árbol" y todo lo que el Árbol simbolizaba, comienzan a aparecer desde el mismo nacimiento del Boletín, (30 citas en el año 1899), pero se concentran claramente en el año 1900, (73 citas localizadas sobre todo en los boletines $\left.n^{\circ}=23\right)$, (25 citas) y no 29 (30 citas)), aparece 1 cita en el año 1901, (boletín no 109) y ya no volvemos a encontrar referencia alguna a este tema en el resto de los años. En función de estos datos, podríamos pensar que el tema del árbol, con los significados de nueva costumbre a establecer en la enseñanza, la promoción de recursos naturales, deseos de productividad, regeneración o nacimiento, etc., continúa como tensión regeneradora, durante todo el período de publicación del Boletín. Algo semejante sucedió con el tema del Regeneracionismo, al que el Boletín dedica más citas los primeros años de su publicación, (16 citas en 1899, 11 citas en 1900 y 12 citas en 1901), y es menos intenso en sus últimos números, (años 1902 y 1903, ( 0 citas en los boletines $\mathrm{n}^{\mathrm{O}}$ 133, $\mathrm{n}^{\mathrm{O}} 137$ y $\mathrm{n}^{\mathrm{O}}$ 150). Esto es una mera inter-

8. Llevaremos a cabo interpretaciones más detalladas de cada categoría en la exposición de nuestras explicaciones teóricas, aquí consideramos sólo los "temas" genéricos más relevantes. 
pretación de resultados, pero tanto la Fiesta del árbol como la vinculación al regeneracionismo fueron cuestiones que se mantuvieron con intensidad durante todos los primeros años del siglo XX; quizá los datos obtenidos en el Boletín señalan que la inicial fuerza "regeneradora" fue aplacándose, pasados los comienzos iniciales, y que la extensión temática del Boletín se dedicó a cuestiones más locales (viajes de los Inspectores, incidencias personales, etc.).

- Las Causas que justificaban los intentos de reforma educativa se expresaron a lo largo de todos los boletines, especialmente en los primeros, (26 citas en el año 1899, 22 citas en 1900, 21 en 1901, 15 en 1902 y 1 cita en el año 1903), constituyéndose así en uno de los ejes que, sobre todo al principio, justificaba la edición del Boletín, esto es, poner de manifiesto los problemas y demandas de los maestros que hacían precisa la introducción de mejoras educativas.

- Siguiendo un proceso inverso al anterior encontramos Fortalezas y Obstáculos al intentar poner en marcha diversas estrategias de mejora, cuando ya habían quedado patentes los problemas y la atención se centraba en el proceso de su resolución. Por ello, este tema parece ser relevante sobre todo en los años 1901 (13 citas) y 1902 (10 citas), aunque estuviera presente desde el inicio del Boletín, (1899 y 1900: 9 citas).

- Así mismo, las Consecuencias de dichas estrategias parecen reflejarse más en el contenido de los boletines sobre todo correspondientes al año 1902, (12 citas 7 de las cuáles asociadas al boletín no 101), mientras que al principio de las reformas, en 1899 apenas se localizan referencias de consecuencias, ( 2 citas en el boletín n⿳ำ 18).

- Los temas Legislativos, importantes a lo largo de todo el Boletín, (26 citas en 1899, 20 en 1900, 25 en 1902 y 15 en 1903), se convirtieron en uno de los centros de los boletines publicados en 1901, (55 citas, 25 de las cuáles asociadas al boletín no 66), lo que no es de extrañar si consideramos que en esos años se decretaron reformas sobre los planes de formación de los maestros o el sistema de pagos.

- Otro tema clave en todos los Boletines estudiados es El Magisterio, o las referencias a la "clase de maestros" sin distinguir asociaciones. No obstante, volvemos a encontrar que el año 1901 fue especialmente rico en referencias de contenido relativas a este tema, (83 citas), seguido del año en que surgió el Boletín, 1899, (66 citas, 34 de las cuáles asociadas al 1er. Número), 1902, (46 citas, 34 de las cuales asociadas al boletín no 101), 1900 (30 citas, 20 de ellas asociadas al boletín $n^{\circ}$ 49) y finalmente, 1903 (6 citas en el $\left.n^{0} 150\right)$.

- En cuanto a aspectos más concretos, (por ej. podemos destacar la Comunicación con otras publicaciones), parecen ser más relevantes durante el año 1902, (sobre todo en los boletines no 101 y 109, 5 y 4 citas respecti- 
vamente), el Concepto de ED/PED caduco, puesto de manifiesto sobre todo al principio de esta publicación, en los boletines de 1900, (12 citas), 1899 y 1901 (7 citas en ambos), mientras que pareció disminuir su importancia como justificación de las reformas educativas a lo largo de los años, 1902 (1 cita) y 1903 (0 citas).

Generación de conocimiento: Interpretación de resultados

A continuación, interpretaremos los datos, tomando como referencia el modelo teórico que generamos con nuestras categorías, ademas de los comentarios interpretativos señalados anteriormente. Para ello, nos basamos en algunas de las herramientas que ofrece el Atlas/ti como son las búsquedas booleanas, (para recuperar las citas asociadas a diversos textos cuyos códigos combinamos mediante operadores booleanos como " $\mathrm{o}$ " " $\mathrm{y}$ " etc.), la recuperación textual espacial, donde recuperamos textos según relaciones de proximidad, (textos que se superponen, se siguen, se incluyen en otros o simplemente co-ocurren) y la recuperación textual semántica, (basada en nuestras redes semánticas).

Para comprobar algunas hipótesis, a modo de "relaciones entre tópicos, identificados en un texto, a partir de los cuales es posible reconstruir un todo estructurado que nos aproxima a una comprensión global de los datos (...) o dicho de otro modo, de posibles regularidades de patrones de significado" (Rodríguez Gómez, G.; Gil Flores, J.; García Jiménez, E. Y Etxeberría, J., 1995)”, llevamos a cabo algunos contrastes, no en el sentido estadístico tradicional, sino como toma de decisiones a partir de la comparación de nuestros datos con una distribución teórica de referencia. En consecuencia, las relaciones entre códigos mostrarían lo que los códigos representan y no las referencias textuales de los códigos.

Por limitaciones de espacio, presentaremos directamente la interpretación de los textos localizados por el Atlas/ti.

\section{Causas del Regeneracionismo}

Partiendo de nuestro fenómeno, (la contribución de la Asociación del Magisterio Riojano al progreso educativo de la época mediante su Boletín), se recogen textos que reflejan diversos problemas organizativo-institucionales percibidos por los maestros como necesidades insatisfechas que justificaban su actuación. Así, localizamos las siguientes causas:

1. Concepto de Educación Caduco.

2. Deficiencias del Sistema Educativo.

2.1. Desprestigio docente.

2.2. Cualificación insuficiente del maestro.

2.3. Contenido inadecuado de la enseñanza. 
2.4. Metodología, excesivamente teórica, de enseñanza.

2.5. Deficiencias en la Inspección.

2.6. Material Escolar Insuficiente.

2.7. Promoción limitada.

\subsection{Insuficiente retribución.}

Para ejemplificar el proceso de comprobación de supuestos que seguimos, describiremos cómo comprobamos la relevancia temática del sistema de retribución-salario del maestro.

El supuesto a comprobar era el siguiente:

"en los boletines uno de los temas importantes es el sueldo de los maestros de tal modo que cuando se alude a los maestros en general, se menciona en un contexto próximo, (por ej. 5 líneas), el tema del sueldo".

El Atlas/ti mostró que del total de citas referidas a "Maestros", (231), 30 de ellas aparecían vinculadas al "sistema de retribución-salarios deficientes" antes o después de "Maestros", lo que supone aproximadamente un 13\% del total. Al no ser esta una cifra muy elevada, en principio, tendríamos que concluir que siendo un tema considerado por los maestros fundamental, al menos no es el único en el que el Boletín centra su atención.

Prosiguiendo nuestros análisis, observamos que la pobreza de los sueldos asignados al maestro, además de su retraso en los pagos y el propio sistema de retribuciones que contemplaba incluso los emolumentos pagados por las familias, constituía un problema clave, a menudo agravado por la legislación inadecuada, que movilizó a los maestros para luchar por mejorar la situación educativa. Ante la insuficiencia y el retraso de los sueldos los maestros demandarán los pagos por parte del estado, convirtiéndose este en un reto esencial para la Asociación del Magisterio Riojano que se logrará, como veremos en las consecuencias, al menos en parte.

\subsection{Legislación inadecuada.}

A modo de ejemplo, señalaremos otro tipo de hipótesis que pudimos comprobar. En este caso se trataba de estudiar hasta qué punto se asociaban las Deficiencias del Sistema Educativo a los aspectos legislativos que habían de regularlos, planteándonos el siguiente supuesto:

"En los boletines, se considera la legislación referida a educación como una de las principales deficiencias del Sistema Educativo, es decir, gran parte de las citas referidas a dichas deficiencias tienen que ver con temas legislativos". 
Para comprobarlo, escribimos la siguiente cadena de búsqueda en el Atlas/ti: SUB "Deficiencias del Sist. Ed." \& Legislación

Al recuperar todas las citas asociadas a la categoría de "Deficiencias del Sistema Educativo" que simultáneamente estuviesen codificadas bajo la categoría de "Legislación", encontramos 31 citas directamente relacionadas con aspectos legislativos que los maestros consideraban inadecuados, (en un total de 152 citas). En particular, las deficiencias educativas asociadas a la legislación se referían al tema de los derechos profesionales de los maestros: Retribución-Salario deficiente, oposiciones, traslados, ascensos, plazas vacantes, la inspección, la obligatoriedad de la enseñanza y las clases nocturnas de los maestros.

2.10. Políticos ineptos.

2.11. Retraso Cultural.

2.12. Insuficiente productividad.

\subsection{Conciencia del "Fracaso Nacional".}

España, concebida como una nación influyente, veía cómo su poder iba mermando con la pérdida de las colonias, (la idea de "patria en peligro", de reconquista del propio suelo se extendía, era preciso seguir el ritmo de otras naciones) y cómo debía afrontar problemas económicos agravados a menudo por los continuos cambios políticos que parecían impedir reformas profundas a largo plazo.

Este sentimiento de desánimo se refleja en el Boletín, (sobre todo en los primeros números), apuntándose como vía de solución la Educación entendida en sentido amplio como "medio de asegurar la cultura pública, la riqueza nacional, el bienestar de las familias, etc.

En definitiva, también la educación se impregna del movimiento regeneracionista de la época que solicita reformas: es imprescindible introducir cambios en la Educación, "misión" -pues como tal conciben esta tarea fundamental del maestro- pero que exige la colaboración de todos los sectores de la sociedad, (sobre todo de las familias y los políticos), para llevarla a cabo.

Para ver si el concepto de regeneracionismo se relacionaba con el de reforma, establecimos el siguiente supuesto:

"En los boletines, se considera el concepto de regeneracionismo vinculado al concepto de reforma, esto es, las referencias textuales sobre regeneracionismo coinciden con las de reformas".

Introduciendo la siguiente cadena de búsqueda en el Atlas/ti:

REGENERACIONISMO COOCCURR REFORMAS

Se localizan 6 citas en que coincidían ambos conceptos. En particular, dichas citas se referían a los ideales de la asociación, a la regeneración promo- 
vida en la fiesta del árbol, a la "misión" salvadora de la patria a desempeñar por el maestro, a la consecución de unión entre maestros y a la necesidad de que el Gobierno solvente "un anacronismo inexplicable", el déficit económico que repercute en los sueldos de los maestros. Por tanto el regeneracionismo se vinculaba con la idea de "crear", también relacionado con el establecimiento de "grandes leyes", la naturaleza, la sobriedad, fidelidad a Dios y a la Patria. Sin embargo es un concepto de Regeneracionismo "especial", por ej., no comparte el laicismo, al contrario, se define claramente por una confesión religiosa comparando al sacerdote con el educador ( $\mathrm{n}^{-}$18, 1899). Se relaciona con la regeneración física y económica del "suelo patrio", que había de reconquistarse; de hecho, en el Boletín aparecen íntimamente relacionados el regeneracionismo y la Fiesta del árbol, (Ilamada también fiesta de los niños, no 29 (198:205), pues a ellos se dirige). Esta última incluso se concibe como una metáfora de dicha reconquista en la que se recuperan terrenos que se daban por perdidos, para formar parte de la riqueza nacional.

\section{Estrategias de mejora.}

Siguiendo nuestro modelo teórico establecido a partir de los boletines analizados ${ }^{9}$, (49 citas referidas a estrategias), podemos considerar que el magisterio riojano en particular, y en general, el magisterio español, puso en marcha diversas estrategias para conseguir esa mejora educativa tan ansiada. De todas estas estrategias, se puede decir que la más importante fue unir a los maestros, a todas las asociaciones representadas en la Asociación Nacional del Magisterio con influencia para pedir reformas a los poderes públicos.

Se plantea el siguiente supuesto:

"Según se refleja en los números del Boletín analizados, las estrategias para mejorar la enseñanza reflejadas en el Boletín se apoyan más en el maestro que en los políticos, esto es, la frecuencia de referencias textuales de estrategias relativas al maestro (fr 1 ) es mayor que la frecuencia de referencias textuales de estrategias relativas a los políticos (fr2)".

Para comprobarla le indicamos al Atlas/ti la siguiente búsqueda de citas con su correspondiente frecuencia:

FR1=ESTRATEGIAS ENCLOSES MAESTROS=27 FR2=ESTRATEGIAS ENCLOSES POLITICOS=8

Como vemos, se cumple lo supuesto en nuestra hipótesis, (fr1>fr2) y, por tanto, se concluye que las estrategias se apoyan más en el maestro que en los políticos. Así, las estrategias más importantes que intentaron desarrollar para promover la mejora educativa fueron:

9. Muchas de ellas aparecen desde el $1^{\text {er }}$ № del Boletín en la propia definición de sus fines. 
3.1. Fortalecer la "Clase del Magisterio".

3.1.1. Favorecer la unión-comunión entre socios.

3.1.2. Promoción de nuevos planes de formación inicial.

3.2. Establecimiento de canales de discusión para la promoción de reformas educativas.

3.2.1. Comunicación con otras instituciones: ayuntamientos, Ministerio, autoridades estatales.

Por ejemplo, en cuanto a la relación del Magisterio con los Ayuntamientos, nos planteamos si dichas relaciones evolucionaron a lo largo del Boletín mediante el siguiente supuesto:

"Las relaciones entre los Ayuntamientos y las diversas Asociaciones del Magisterio español fueron variables a lo largo de los años".

Tras plantear la siguiente cadena de búsqueda al Atlas/ti:

(Asoc. Magisterio ENCLOSES AyUntamiento POR FAMILIA DE BOlETINES)

Ante estos resultados debemos indicar que, si bien existían muchos casos de entendimiento entre las asociaciones y los ayuntamientos, fue precisamente en el tema de los pagos al maestro donde encontramos los mayores problemas entre ambos. No es de extrañar entonces que dichas relaciones evolucionaran conforme cambiaron las condiciones de pago al magisterio, cuando pasó a ser función del Estado.

3.2.2. Comunicación con otros colectivos de maestros: la Asociación del Magisterio Madrileño y la Asociación del Magisterio Gerundense

Parece claro que, desde el Boletín, se hizo un verdadero esfuerzo por establecer esas vías de comunicación. No obstante, lo más importante conforme el objetivo de nuestro estudio fue su finalidad: promover reformas. Por supuesto, dentro del respeto a las propias leyes y conscientes de los "intereses" que había que respetar (manifestación de realismo). No querían una gran revolución, sino la introducción de reformas: "sin choque violento" (nº18, 1899), "consagraría la suma de intereses creados y sin crear (...). No se trata de una reforma profunda" (no 47, 20 julio 1900).

\subsubsection{Comunicación con otras publicaciones.}

¿Sobre quién recaía el protagonismo de dichas reformas? Según el Boletín era la figura del maestro. Para analizar este aspecto, nos planteamos el siguiente supuesto:

"El Magisterio percibe que es responsable en la reforma de la enseñanza, es decir las referencias textuales del Boletín sobre la reforma que se Vin- 
culan a las Asociaciones de magisterio deberían ser más numerosas a las referencias que no se vinculan a las Asociaciones de Magisterio en un contexto próximo, (5 líneas)".

Se trataba de analizar si cada vez que se trataba el tema de reformas en el Boletín se incluían citas codificadas con la categoría de Asociaciones de Magisterio, o paralelamente, si no existían citas codificadas con la categoría de reforma que no estuviesen al mismo tiempo codificadas con las de magisterio. Al introducir en el Atlas/ti las siguientes cadenas de búsqueda:

REFORMA NO AsOCIACIONES DE MAGISTERIO

\section{ASOCIACIONES DE MAGISTERIO OVERLAPPED BY REFORMAS EDUCATIVAS}

En contraste con lo esperado, (el maestro era el auténtico protagonista de las reformas), encontramos 41 citas relativas a las reformas educativas no codificadas con la categoría del magisterio y sólo 16 referidas a las reformas y a las Asociaciones de Magisterio. Aunque en principio parecería que debíamos rechazar nuestra hipótesis, sin embargo, al leer detenidamente las citas descubrimos que a menudo no existían referencias directas a las asociaciones de magisterio, pero sí a los maestros. Por tanto, estudiando los textos llegamos a la conclusión de que el maestro sí que se considera en el Boletín como el auténtico protagonista de las reformas, pero se centran en la figura genérica del maestro sin vincularla específicamente a ninguna Asociación. Esto es, las reformas son responsabilidad de cualquier maestro y empiezan por su propio contexto de trabajo, no deben recaer exclusivamente en los maestros pertenecientes a una asociación. Estas reformas, como hemos ido viendo, fueron de diversos tipos. Desde aquellas que trataban cuestiones metodológicas, nueva metodología, "de apertura, de intuición, de productividad" (no 18, 1899). Cuestiones nucleares, como una nueva educación que fuese integral, abierta a la naturaleza, ( $\mathrm{n}^{-0}$ 18, 1899), estética y obligatoria (no 29, 1900), son las que consideraban los aspectos económicos de la enseñanza

4. Fortalecer infraestructuras educativas

4.1. Centros de formación (Escuelas Normales)

4.2. Promover la extensión de niveles educativos (Ed. de adultos)

\section{Obstáculos}

El desarrollo de las estrategias anteriores se vio obstaculizado por diversos factores que coincidían con los mismos problemas o causas del fenómeno que habían originado dichas estrategias. ¿Podemos decir que en el Boletín cada vez que se trata el tema de las reformas educativas se reflejan los obstáculos que habrían de superarse?, ¿se percibe la tarea de reformar la educación como un auténtico reto lleno de obstáculos? 
La búsqueda, [("Reformas Ed." ENCLOSES "MAESTROS=*ASOCIACIONES MAGISTERIO*Asociación Mag..") FOLLOWS:5 "OBSTÁCULOS"], mostró que sólo en dos ocasiones aparecen tan próximos obstáculos y reforma, de ahí que no podamos concluir que existiese ese "pesimismo" en el magisterio en cuanto al posible éxito de las mismas. Ahora bien, ¿aumentaron los obstáculos a las reformas percibidos por los maestros? Para responder a esta cuestión elaboramos un nuevo supuesto:

"Con el tiempo, se perciben más obstáculos para conseguir la mejora educativa, esto es, la frecuencia de la categoría "Obstáculos" aumenta en función de los años de publicación del Boletín."

Tras calcular las frecuencias textuales para ver si efectivamente eran crecientes, concluimos que, parecía existir cierto pesismismo, pues aumentaba el $\mathrm{n}^{\circ}$ de obstáculos percibidos por los maestros, (reflejados en el Boletín), hasta el año 1901, invirtiéndose la tendencia desde 1902. Una posible explicación a este hecho es que conforme se sucedían los primeros años de vida del Boletín al entusiasmo por las reformas inicial se fue añadiendo el realismo y la descripción más detallada de los obstáculos que iban encontrando al desarrollarse estrategias. No obstante, al conseguir algunos logros hacia el año 1902, la percepción sobre el éxito de las reformas fue más positiva. Sintéticamente, señalamos los obstáculos encontrados:

\section{Legislativos.}

1.1. Retraso en las reformas.

1.2. Legislación inadecuada.

2. Económicos.

2.1. Presupuestos insuficientes dedicados a la Educación.

3. Educativos.

3.1. Analfabetismo, absentismo escolar, ausencia de graduados.

3.2. Inspección politizada.

3.3. Excesiva movilidad de maestros.

4. Politicos.

4.1. Caciquismo.

\section{Fortalezas}

No obstante, a lo largo de los boletines encontramos otros factores percibidos por los maestros como fortalezas de la actividad educativa. Así destacamos entre todos ellos las fortalezas referidas al: 


\section{El regeneracionismo.}

2. Algunos políticos.

3. La "Sociedad".

4. Editoriales.

5. Los inspectores.

\section{Consecuencias}

Respecto a las consecuencias de las estrategias adoptadas que se reflejan en el Boletín, que hemos extraído del texto recuperando la categoría de "Consecuencias", parece confirmarse que en efecto se llevaron a cabo algunas de las reformas tan demandadas por los maestros, reflejadas en nuevas disposiciones legales, o modificación de las anteriores.

Consecuencias del fortalecimiento de la "Clase del Magisterio", (Defensa de los derechos profesionales del maestro referidos al sistema de retribución-pagos, comunicación entre socios y formación inicial).

$\stackrel{\leftrightarrow}{\rightarrow}$ Evolución del sistema de retribución-pagos, que van pasando del entusiasmo inicial al ver cumplidas algunas de sus mayores aspiraciones, (por ej. el pago de los sueldos por parte el Estado) hasta la crítica por lo incompleto de la reforma.

$\stackrel{\leftrightarrow}{\rightarrow}$ Iniciativas de unión entre los maestros, como la creación de las distintas asociaciones provinciales de magisterio y la concentración de todas ellas en una Asociación Nacional de Magisterio, ( $n^{-0} 47,20$ de julio de 1900), la Asociación de Amigos de la Fiesta del Árbol, (nº 21, 5 de enero de 1901), la publicación de una "Cartilla forestal" de D. Santiago Arnal, (inspector de $1^{\text {a }}$ enseñanza de Barcelona), con la que comenzaba a funcionar la biblioteca circulante, la celebración de diversos encuentros entre los cuáles destacamos la asamblea de "amigos de la enseñanza" en la que participó el ministro de instrucción pública, cuya crónica nos ofrece el no 98 del boletín.

$\stackrel{4}{\rightarrow}$ Repercusiones sobre la formación inicial de los maestros, como la rectificación de la Real Orden de 17 de febrero en respuesta a la solicitud de varios maestros de cursar en un solo año, (en vez de 2) las asignaturas que les faltan para revalidarse como maestros superiores.

* Consecuencias de establecer canales de comunicación-discusión, (con instituciones, colectivos y otras publicaciones), para promover reformas educativas:

$\stackrel{4}{\rightarrow}$ Una mayor comunicación con diversas instituciones, entre ellas el Ministerio de Instrucción Pública, reforzada por la actitud positiva de algunos ministros como el Conde de Romanones, tuvo al parecer impli- 
caciones directas no sólo en la mejora del prestigio del maestro, sino lo que es más importante, en las reformas legislativas de carácter educativo y sobre el sistema de retribución y pagos al mismo.

$\leftrightarrow$ La nueva reforma legislativa se recoge en el no 137 (25 de noviembre de 1902), donde se expone la Real Orden del 11 noviembre que modifica la R.O. de 30 de septiembre sobre la dotación de material para las clases de adultos en las escuelas públicas de instrucción primaria.

Consecuencias del fortalecimiento de infraestructuras: la Inspección, las Escuelas Normales, extensión de la educación, (educación de adultos).

$\leftrightarrow$ La reforma de las Escuelas Normales y de la Inspección de la $1^{a \underline{a}}$ enseñanza.

$\leftrightarrow$ Licencias para que los maestros pudiesen ampliar estudios, (Real Orden de 21 de marzo de 1903, no 150 del 15 de abril de 1903).

$\Leftrightarrow$ Un proyecto de Decreto para subsanar las dificultades prácticas surgidas como consecuencia del sistema de provisión de plazas previsto anteriormente en el R.D. de 31 de mayo de 1902.

\section{Conclusiones}

Después de llevar a cabo un análisis de contenido sobre el Boletín de la Asociación del Magisterio Riojano con ayuda del programa de análisis cualitativo Atlas/ti, (bajo los presupuestos teóricos de la Ta fundamentada) y tras elaborar un esquema teórico explicativo del papel del Boletín en la introducción de mejoras educativas en el contexto socio-político-educativo de la época, (determinar las condiciones causales del cambio educativo, las estrategias desarrolladas, los aspectos facilitadores u obstáculos y las consecuencias de tales estrategias), Ilegamos a las siguientes conclusiones.

- Respecto al Boletín como publicación podemos destacar que:

$\leftrightarrow$ La mayor parte de los boletines se dedicaban a la transmisión de noticias, y en su $1^{\text {a }}$ página presentaban el tema central a considerar en el boletín normalmente referido a aspectos "oficiales", legislación, (aunque sólo se la define como tal sección en 1 boletín) y en menor medida a crónica de actividades, correspondencia o artículos firmados.

\section{* En cuanto a los temas predominantes:}

$\stackrel{\leftrightarrow}{\rightarrow}$ En general, el aspecto económico predomina en todo el Boletín, tanto en los problemas como en la demanda de soluciones, eso sí, vía legislación, pues la legislación sería la garantía de los pagos. Tanto en las causas como en las estrategias como en los obstáculos el aspecto económico es el más destacado. No se dedica tanto espacio del boletín a discusiones didácticas o filosóficas sobre la educación, se trata más 
bien de luchar por generalizar esa enseñanza obligatoria con unas mínimas garantías de funcionalidad.

$\leftrightarrow$ Los boletines reflejaban más o menos explícitamente, gran diversidad temática. Por supuesto, el tema prevalente, el centro temático del Boletín, era el Magisterio Español, y dentro de este, el Magisterio Riojano. No obstante, el Boletín se dirigía a los maestros riojanos, pero deseaba ir más allá de ellos mismos, ofreciendo y recogiendo informaciones sobre los maestros "en general", tal vez para fomentar con ello la conciencia de unidad como "clase de magisterio".

$\stackrel{\leftrightarrow}{\rightarrow}$ La legislación educativa, pareció convertirse en el segundo protagonista del boletín, ya fuesen textos legislativos literales, comentarios a los mismos e incluso argumentaciones sobre la situación del magisterio basadas en leyes que se consideraban inadecuadas.

$\stackrel{4}{4}$ La Fiesta del Árbol, tema fundamental del Boletín, estrechamente vinculado a la necesidad de reformas, de sentimientos de regeneración, que estudiaremos en profundidad más adelante.

$\stackrel{4}{4}$ Otros aspectos como las demandas del magisterio y, en particular, los problemas referidos al sistema de retribución de los maestros y sus salarios parecen ser atendidos ampliamente en nuestros boletines, así como las reformas educativas.

Respecto a los problemas que suscitan las reformas, (causas), según nuestro modelo teórico, el concepto de Educación/Pedagogía caduco por sí mismo, provocaría la necesidad de mejorar la educación, pero encontramos además otro gran motivo, lo que hemos denominado "las deficiencias del sistema educativo" entre las que podrían enumerarse las "deficiencias en la inspección", los "materiales y contenidos escolares insuficientes", la "metodología excesivamente teórica", la "cualificación del maestro insuficiente", que contribuye a "desprestigiarlo" socialmente y las "limitaciones de su promoción" estrechamente vinculadas a un "sistema de retribución-salario del maestro deficiente". Además nos encontramos con una "legislación inadecuada", que origina las limitaciones anteriores referidas a los pagos del maestro, desarrollada por "políticos ineptos" que contribuyen a aumentar la "conciencia de fracaso nacional", alimentada también por el "retraso cultural". Este "retraso cultural" se debería tanto al contenido de enseñanza insuficiente, como a la metodología excesivamente teórica y a su vez contribuiría a retrasar la productividad económica insuficiente en opinión del magisterio riojano.

$\leftrightarrow$ La pobreza de los sueldos asignados al maestro, además de su retraso en los pagos y el propio sistema de retribuciones que contemplaba incluso los emolumentos pagados por las familias, constituía un problema cla- 
ve, a menudo agravado por la legislación inadecuada, que movilizó a los maestros para luchar por mejorar la situación educativa.

$\leftrightarrow$ Las deficiencias educativas asociadas a la legislación se referían al tema de los derechos profesionales de los maestros: Retribución-Salario deficiente, oposiciones, traslados, ascensos, plazas vacantes, la inspección, la obligatoriedad de la enseñanza y las clases nocturnas de los maestros. Se critica la legislación vigente en aquella época, elaborada y desarrollada por "políticos ineptos" con dos repercusiones especialmente importantes, limitar las posibilidades de promoción de los maestros y plantear, un sistema de retribución-salario deficiente.

* La Fiesta del Árbol supone un intento importante, (exitoso, al menos los primeros años), de regeneración económica y política, de modo que centrándose en algo tan concreto como la repoblación forestal pretende ir más allá intentando fomentar la regeneración de costumbres, nuevos contenidos educativos, una metodología activa, etc. La Fiesta del Árbol se considera la $1^{\text {a }}$ reforma a emprender, un ideal regenerador, ejemplo de productividad y recurso metodológico para "inculcar respeto".

* El regeneracionismo se vinculaba con la idea de "crear". Sin embargo es un concepto de Regeneracionismo "especial", por ej. no comparte el laicismo, al contrario, se define claramente por una confesión religiosa comparando al sacerdote con el educador. Se relaciona con la regeneración física y económica del "suelo patrio", que había de reconquistarse de hecho, en el Boletín aparecen íntimamente relacionados el regeneracionismo y la Fiesta del árbol.

\section{* En cuanto a las estrategias:}

$\leftrightarrow$ Podríamos decir que la más importante fue unir a los maestros, a todas las asociaciones representadas en la Asociación Nacional del Magisterio con influencia para pedir reformas a los poderes públicos, (se apoyan más en el maestro que en los políticos).

$\stackrel{\leftrightarrow}{\rightarrow}$ El Boletín contribuyó a la unión del magisterio estimulando la colaboración entre todos los maestros, difundiendo información sobre la creación de nuevas asociaciones, explicando los acuerdos conseguidos en las reuniones, etc.

$\stackrel{\leftrightarrow}{\hookrightarrow}$ Destacó la preocupación por extender la educación a los adultos.

* En cuanto a los obstáculos a la puesta en marcha de reformas, cabe destacar el retraso en las reformas, la legislación inadecuada, la insuficiencia de recursos económicos, el analfabetismo, los criterios, (no técnicos) en la elección de inspectores, la excesiva mobilidad de los maestros y el "caciquismo". 
Respecto a las fortalezas, las reformas se apoyaron en las ideas regeneracionistas, algunos ministros e inspectores, la sociedad e iniciativas editoriales.

* Como consecuencia de las estrategias anteriores y del propio contexto socio-político de la época:

$\stackrel{\leftrightarrow}{\rightarrow}$ Vemos la transición del entusiasmo inicial al ver cumplidas algunas de sus mayores aspiraciones, (por ej. el pago de los sueldos por parte del Estado) hasta la crítica por lo incompleto de la reforma.

$\stackrel{m}{\rightarrow}$ Se multiplican las iniciativas de unión entre los maestros, como la creación de las distintas asociaciones provinciales de magisterio y la concentración de todas ellas en una Asociación Nacional de Magisterio.

$\stackrel{\leftrightarrow}{\rightarrow}$ Consiguieron una mayor comunicación con diversas instituciones, entre ellas, el Ministerio de Instrucción pública.

$\Leftrightarrow$ Se inició la reforma de las Escuelas Normales y de la Inspección.

$\leftrightarrow$ Se reformó el sistema de promoción y provisión de plazas del magisterio.

\section{Bibliografía}

ANDRÉS-GALLEGO, J. (1988). Un 98 distinto. Restauración, desastre, regenaracionismo. Madrid: Encuentro.

CASTRO MONERO, M de los A. (1998). Un promotor de la renovación pedagógica española: Manuel Bartolomé Cossío. Investigaciones históricas, 18, 235-247.

CHEVALIER, F. (1979). América Latina de la independencia a nuestros días. Barcelona: Labor.

DÍAZ PLAJA, F. (1971). La historia de España en sus documentos, (del desastre de 1898 al príncipe Juan Carlos). Barcelona: Plaza-Janés.

DUROSELLE, J.B. (1974). Europa de 1815 a nuestros días. Barcelona: Labor.

ESCOLANO, A. (2002). La educación en la España de la Restauración y la Segunda República. En A. Tiana, G. Ossenbach y F. Sanz, Historia de la Educación (Edad contemporánea) (pp. 233-255). Madrid: UNED.

FERNÁNDEZ ALMAGRO, M. (1968). Historia política de la España contemporánea (1897-1902). Madrid: Alianza Editorial.

GARCÍA DEL DUJO, A. (1985). Manuel B. Cossío y el Museo Pedagógico Nacional. Bordón, 37 (258), 367-383.

GERBOD, P. (1982). Europa cultural y religiosa de 1815 a nuestros días. Barcelona: Paidós.

GIL FLORES, J. (1994). Análisis de datos cualitativos. Aplicaciones a la investigación educativa. Barcelona: PPU. 
GÓMEZ MOLLEDA, M.D. (1966). Los reformadores de la España contemporánea. Madrid: CSIC.

GÓMEZ MORENO, A. (1994). Regeneracionismo y educación en España (1900-1923): análisis de un fracaso (tesis). Zaragoza: Universidad de Zaragoza.

HERNÁNDEZ FRAILE, P. (1987) Museo pedagógico nacional. Boletín de la Anabad, 37 (4) 615-629.

KRIPPENDORF, K. (1997). Metodología del análisis de contenido. Teoría y práctica. (1a reimpresión). Barcelona: Paidós Ibérica.

MARTÍNEZ CUADRADO, M. (1974). Historia de España Alfaguara: La burguesía conservadora (1874-1931). Madrid: Alfaguara.

MÉRIDA, E. (1990). La Revista de Pedagogía y su influencia en el Magisterio Español: 1922-1936 y 1978. (Tesis). Barcelona: Universidad de Barcelona, Facultad de Filosofía y CC. de la Educación.

MILES, M.B. y HUBERMAN, A.M. (1994). Qualitative Data Analysis: a sourcebook of new methods, (2 ${ }^{\mathrm{a}}$ ed.). Tousand Oaks, Ca.: Sage.

MORENO LUZÓN, J. (2002) (Ed.). Regeneracionismo y reforma. Madrid: BBVA.

MUHR, Th. (1997). Atlas/ti Visual Qualitative Data Analysis-ManagementModel Building-Release 4.1. User's manual. (1 ${ }^{\text {st }}$ ed.). Berlín: Scientific Software Development.

OTERO, E.M. (1990). Pensamiento pedagógico y acción educativa de Manuel Bartolomé Cossío. (Tesis). Asturias: Universidad de Oviedo.

POZO, Ma M. del (1994). Ciento cincuenta años de perfeccionamiento del Magisterio en España: desde las Academias de profesores a la creación de Ios CEPs, 1840-1984. (Tesis). Madrid: Universidad de Alcalá de Henares.

POZO, M.M. del (2000). Curriculum e identidad nacional (regeneracionismos, nacionalismos y escuela pública. 1890-1939). Madrid: Biblioteca Nueva.

PUELLES, M. de (1999). Educación e ideología en la España contemporánea. Madrid: Tecnos.

RODRÍGUEZ GÓMEZ, G.; GIL FLORES, J.; Ga JIMÉNEZ, E. y ETXEBERRÍA, J. (1995). Análisis de datos cualitativos asistido por ordenador: AQUAD y NUDIST. Barcelona: PPU.

SAN ROMÁN, S. (1998). Las primeras maestras: los orígenes del proceso de feminización docente en España. Barcelona: Ariel.

SASTRE, J.L. (1989). Antecedentes, evolución y estructura de una publicación centenaria en educación: el Magisterio Español. (Tesis). Madrid: UCM.

VALVERDE, J. (1990) (Ed.). La restauración (1874-1902). Barcelona: Planeta. 